\title{
Impact Assessment of Orography on the Extreme Precipitation Event of July 2010 over Pakistan: A Numerical Study
}

\author{
Khan Muhammad Tahir,, ${ }^{1,2,3}$ Yan Yin, ${ }^{1,4}$ Yong Wang, ${ }^{3}$ Zaheer A. Babar,, ${ }^{2,3}$ and Dong Yan \\ ${ }^{1}$ Key Laboratory for Aerosol-Cloud-Precipitation of China Meteorological Administration, Nanjing University of \\ Information Science \& Technology, Nanjing 210044, China \\ ${ }^{2}$ Pakistan Meteorological Department, Islamabad 44000, Pakistan \\ ${ }^{3}$ College of International Education, Nanjing University of Information Science \& Technology, Nanjing 210044, China \\ ${ }^{4}$ Collaborative Innovation Center on Forecast and Evaluation of Meteorological Disasters, Nanjing University of \\ Information Science \& Technology, Nanjing 210044, China \\ ${ }^{5}$ Beijing Meteorological Bureau, No. 44 Zizhuyuan, Haidian, Beijing 100089, China
}

Correspondence should be addressed to Yan Yin; yinyan@nuist.edu.cn

Received 26 November 2014; Revised 13 February 2015; Accepted 13 February 2015

Academic Editor: Sven-Erik Gryning

Copyright (C) 2015 Khan Muhammad Tahir et al. This is an open access article distributed under the Creative Commons Attribution License, which permits unrestricted use, distribution, and reproduction in any medium, provided the original work is properly cited.

\begin{abstract}
The topography influences monsoon precipitation and gives rise to significant rainfall events in South Asia. The physical mechanism involved in such events includes mechanical uplifting, thermodynamics, small scale cloud processes, and large scale atmospheric circulations. The investigation into orographic precipitation is pursued by synoptic and model analysis. Deep convection occurs as warm moist airflow is channeling over steep mountains. WRF model coupled with Morrison double moment scheme is used to assess the relative impact of topography on extreme rainfall event of 26-30 July 2010 in Pakistan. Two sensitivity tests with full topography (CTL) and reduced topography by $50 \%$ (LOW) are carried out. Two distinct precipitation zones over Hindukush and Himalaya mountains are identified. The topographic changes significantly affect moisture divergence and spatial and temporal distribution of precipitation. A low level jet is created on windward side of big mountains, yielding enhanced moisture flux and instability. Eddy kinetic energy significantly changes with orographic height. Energy flux created further unstabilized atmosphere and deep convection, producing wide spread heavy rainfall in the area in Himalaya foothills. Under the set synoptic conditions, orographic orientation enhanced the moisture accumulation and deep convection, resulting in occurrence of this extreme event.
\end{abstract}

\section{Introduction}

Summer monsoon brings heavy rainfall in the narrow mountainous belt of north Pakistan where Himalaya meets the Hindukush mountains. These extreme rainfall events resulted in large scale floods [1], leaving behind devastating losses to the economy. According to a WMO [2] report, more than 1700 casualties occurred and 20 million people became homeless in just one heavy rainfall event of July 2010 . The total economic losses were more than 40 billion US dollars during this event.

South Asian Monsoon is a regular phenomenon, characterized by wet summer and caused by seasonal reversal of wind $[3,4]$. Land sea distribution, annual cycle of radiation, and presence of big mountain ranges are the three primary factors affecting South Asian Monsoon (SAM) [58]. The influence of topography on precipitation gives rise to significant rainfall events during monsoon in the South Asian region. Barros et al. [9] pointed out that $20-30 \%$ of the seasonal rainfall over the Himalayan region can pour out from a specific synoptic scale event. The monsoon events intensity depends upon the magnitude of the temperature gradient induced by the land sea heating contrast [10]. The existence of the land sea distribution like Arabian Sea, South Asia, and Bay of Bengal (BoB) plays a significant role in the monsoon circulation, its intensity, and precipitation in this region $[7,8,11]$. However, this traditional theory is not adequate to explain the present day South Asian Monsoon. Pakistan, being part of this region, has diversified topography and extremely variable climate, ranging from subhumid to 
humid in north and arid in south. The north Pakistan is lying along the junction of Himalaya and Hindukush mountain ranges and is declared as the most vulnerable area for the deep and wide convection, where height can reach up to greater than $10 \mathrm{~km}$ [12]. Size and shape of these mountains significantly influence the ultimate distribution of ground precipitation. The spatial distribution of the rainfall over and near the complex terrain features and topography heights is determined by the dynamical behavior of the weather system and thermodynamics of the incoming moist air stumbling upon the terrain barrier. Tibetan Plateau being the heat source also helps in strengthening the intensity of the Asian summer monsoon $[6,7,13,14]$.

Roe [15] mentioned orographic precipitation as ephemeral phenomenon from an existing system resulting in substantially varying spatial distribution of rainfall. Barros et al., Zipser et al., and Houze et al. [16-18] have regarded north Pakistan as region for extremely deep convective zone and tallest lightening prone storms in the world. These convective events can yield extreme local rainfall when moist air from the sea encounters the mountains and thus quasistationary deep convection with highly efficient warm rain coalescence processes producing the effectual downpour of precipitation and flash floods [19].

Berg et al. [20] related the increase in convective scale precipitation with the increase in energy fluxes. During the present global warming time, the moist currents travelling across the mountainous region may adjust in location, strength, and intrinsic instability, causing changes in spatial distribution of rainfall and associated latent heat of the atmosphere. One of the most prominent impacts of the mountain on the lower atmosphere is upstream blocking [21]. The complex terrain of mountains, its orientation to the moisture sources, and impact on atmospheric precipitation cannot be generalized. In case of two-dimensional mountain barriers, it results in upstream blocking to the strong low level flow parallel to the terrain axis [22]. This is caused from the down gradient geostrophic acceleration along the barrier direction $[23,24]$. This blockage in the lower atmosphere occurs, when the fluid flow is perpendicular to the terrain and is determined by Froude number with values less than the threshold of $1.0[25,26]$. A similar case was observed by Bjerknes and Solberg [27] stating that a warm front mutilated as it approaches the Norwegian coast with lower tropospheric portion precluded from passage across the complex topography.

The environmental aspect of increasing rainfall in the lower and high latitude mountainous regions was discussed by many scientists $[28,29]$ who made detailed analysis of dynamical and microphysical processes in the stable/unstable flow over terrain. They found that extreme rainfall event arises upon the overrunning of air layer on the steep mountain ranges in the form of moist low level jet, while the flow is persistent over a substantial time period. Chen et al. [30] found similar results for an extreme convective rain event in Taiwan when circulation around a sub-synoptic Low pressure is generated on a low level shear zone and formed a low level jet of moist unstable air intersecting the central mountain range. Precipitation distribution in the Alps and
Apennines has also been correlated to both the degree of flow, being blocked by the topography (e.g., Medina and Houze, 2003 [31]), and the extent of entrainment of moist low level flow into unblocked flow aloft [32]. Romatschke and Houze [12] revealed that the systems with deep convective cores are sturdily systemized by processes near and over the mountains. This occurs in the proximate regions of the mountain ranges with maximum frequency of incidence during the afternoon and in the early morning.

Many studies on the heavy rainfall events in South Asia have been made $[31,33,34]$ and revealed that local deep storm characteristically occurs near the boundary of the dry air coming across Afghan Plateau and moist air flow at low altitude from the Arabian Sea. The combination of these airflows yields in highly buoyant storm cell and does not form the large stratiform precipitation area. The convective storm obtains energy from the vertical stratification of atmospheric temperature and water vapor [35]. Bay of Bengal (BoB) currents accompanied by the extensive stratiform cloud system carry moisture along the Himalaya, reinforced by the upslope flow [31]. The extreme rainfall event occurred in northern Pakistan during the last week of July 2010, but it rarely happened in the eastern Himalayan region. Lau and Kim [36] assumed that the thermodynamic effect is responsible for this heavy precipitation event. Galarneau et al. [37] linked the Russian heat wave to this event. $\mathrm{Xu}$ and Emanuel [38] revealed that convection is too large over the tropical regions. The rain region in 2010 extreme rainfall case was predominantly stratiform with horizontal coverage of about $200 \mathrm{~km}$. Liu et al. [39] mentioned that interaction between the monsoon currents and the blocking western waves produces the severe weather in Pakistan.

The upper level anomaly of potential vorticity (PV) plays a substantial role in the deep convection of the surface weather systems resulting in heavy precipitation event [40, 41]. Negative moist potential vorticity amplifies the moist symmetric instability and is accompanied by deep convection [42]. If slight potentially unstable layer is embedded in a mesoscale convective system (MCS), deep convection may occur in the existing cloud system as it moves across the terrain [33]. These vast systems from BoB are located in MCS and are disposed by the orographic lifting and can be observed in the radar echoes [43]. Zipser et al. [17] also mentioned that deepest convective towers occur in relatively arid regions. In Himalayan case these are frequently observed in the valleys of the high terrain, where Himalayas are intersected by the Hindukush Plateau.

Mapes et al. [50] mentioned that heating on high mountains in the day time may activate the gravity waves that travel away from the region and produce high convective clouds in the later part of the day. Romatschke and Houze [12] stated that the diurnal wave transmitted strong MCSs, to southward of $\mathrm{BoB}$, due to heating along the east coast of India, during premonsoon period.

The capping and triggering are the key processes in the regions near the Himalaya, where the precipitation cloud system with deep convective cores concentrates in Pakistan near the western end of the Himalayas [12]. Their recurrence rate is very high in the notch of the high terrain where 
TABLE 1: Summary of the physical parameterization schemes, used in this study.

\begin{tabular}{lcc}
\hline Parameter & Parameterization scheme & Reference \\
\hline Long wave radiation & RRTMG & Morrison et al., 2005 [44] \\
Shortwave radiation & RRTMG & Baker et al., 2002 [45] \\
\hline Microphysics & Morrison 2-mom & Iacono et al., 2000 [46] \\
\hline Subgrid scale precipitation & Kain Fritsch & Kain and Fritsch, 1993 [47] \\
\hline Surface layer processes & Monin-Obukhov scheme & Chen and Dudhia, 2001 [48] \\
\hline Boundary layer & YSU scheme & Hong et al., 2006 [49] \\
\hline
\end{tabular}

the western end of Himalaya intersects the Afghan Plateau. Tibetan Plateau is a significant elevated heat source and its importance for rapid seasonal changes effects such events and has been discussed by many authors [51-53]. The precipitation rate in this area is related to the degree of flow blocked by topography [31] and amount of entrainment of moist low level air in the unblocked air aloft [32]. Due to high unpredictability in catchment areas of this region, rainfall variability and extreme weather events became very important factors, especially during the monsoon season. The IPCC AR4 [54] reveal that frequency of such extreme events increased and its future trends shown are "likely to increase" during the 21st century. This area received a historical extreme event during the last week of July 2010, resulting in flash flooding and devastating destruction.

The aim of the present study is to identify the relative impact of orography (mechanical) and thermodynamics on the heavy precipitation event in this area. In this regard, extreme rainfall event of 26-30 July, 2010, has been selected for study. The changes in the regional circulation and moisture flux from two different sources BoB and the Arabian ocean affect the rainfall in this mountainous range. The investigation of orographic precipitation is pursued by two tracks, synoptic and model analysis. The study is organized in 5 parts: Model description and methodology are described in Section 2; synoptic evolution of the system is discussed in Section 3. Model outputs are analyzed in Section 4. Conclusions are presented in Section 5.

\section{Data and Methodology}

A heavy precipitation event occurred from 26 to 30 July, 2010, and produced rainfall along the foothills of Himalaya and Hindukush region. This event resulted in a devastating flood in the region and brings large scale destruction. In this study, attentions would be focused on examining the relative impact of orography and thermodynamics on this rainfall event. This research study is divided into two ways. In the first part synoptic and mesoscale overview of the event has been examined. The reanalysis dataset of the National Center for Environmental Prediction (NCEP)/National Center for Atmospheric Research (NCAR) [55] for the period of 19792010 has been used for the diagnostic and correlative analysis. The spatial resolution of FNL data is $1^{\circ} \times 1^{\circ}$ and is from $180^{\circ} \mathrm{W}-180^{\circ} \mathrm{E}$ and $90^{\circ} \mathrm{S}-90^{\circ} \mathrm{N}$. Eighteen stations of Pakistan Meteorological Department (PMD) observational network have been chosen from the affected area, to obtain the surface observational data. Figure 1(b) indicates domain d03 showing location, topography, and precipitation measured by each of the PMD observing stations during the event of July 2010.

Three representative stations of Kotli, Islamabad, and Saidu Sharif have been selected on the basis of their geographical location in the system path. Their observed temperature, dew point temperature, pressure, and relative humidity $(\mathrm{RH})$ have been drawn. The intensity and location of the Tibetan High during the period have also been calculated, as some studies mentioned that Tibetan Plateau is the main heat source and driving factor of the South Asian Monsoon (SAM) intensity $[7,14]$.

To understand the temporal and spatial evolution of the event, advanced research weather forecasting model ARW-WRF (3.4.1), coupled with Morrison double-moment microphysical scheme [53], has been used for simulation. The scheme is able to predict the concentration and mass mixing ratio of the five hydrometeors, like cloud, rain ice, snow, and graupel. In Morrison scheme, time evolution of hydrometeor concentration and mixing ratio are calculated by grid scale convective detrainment, advection, turbulence diffusion, and other microphysical processes.

The model was designed to have three nested domains $\mathrm{d} 01, \mathrm{~d} 02$, and $\mathrm{d} 03$ with resolution of 27,9 , and $3 \mathrm{~km}$, respectively (Figure 1). The third domain is focused on the core precipitation region with its spatial extension from $30^{\circ} \mathrm{N}-$ $37^{\circ} \mathrm{N}$ to $68^{\circ} \mathrm{E}-78^{\circ} \mathrm{E}$ (Figure 1(a)). Two sensitivity tests, with the full (CTL Case) and reduced topography up to 50\% (LOW case), have been carried out for the period beginning from 0000 UTC of 26 July and ending at 0000 UTC of 30 July, 2010. The six hourly FNL GRIB-I format data of $1^{\circ} \times 1^{\circ}$ resolution have been used as input to specify the initial atmospheric conditions and its evolution along the boundaries (i.e., boundary conditions), for the entire retrospective simulation time period. The GRIB-I dataset (compact data files) has been expanded over the three nested domains. The geographical resolution of the d01, d02, and $\mathrm{d} 03$ is $10 \mathrm{~m}, 2 \mathrm{~m}$, and $30 \mathrm{~s}$, respectively, whereas 35 vertical levels have been envisaged. The grid points in domain d01 are 253 and 246, in d02 298 and 298, and in d03 328 and 301 in the EW and SN directions, respectively. The Lambert Map projection is used in the model. The model configuration and the parameterization schemes used in the model are given in Table 1. The time-split small step for acoustic and gravity-wave modes has been used in the model. The reference latitude and longitude are $30^{\circ} \mathrm{N}$ and $74^{\circ} \mathrm{E}$, respectively. The cumulus physics has been kept on, for outer two domains d01 and d02 only, with call step of five minutes time. Heat and moisture fluxes from the surface, vertical velocity with damping, and eddies coefficient with 


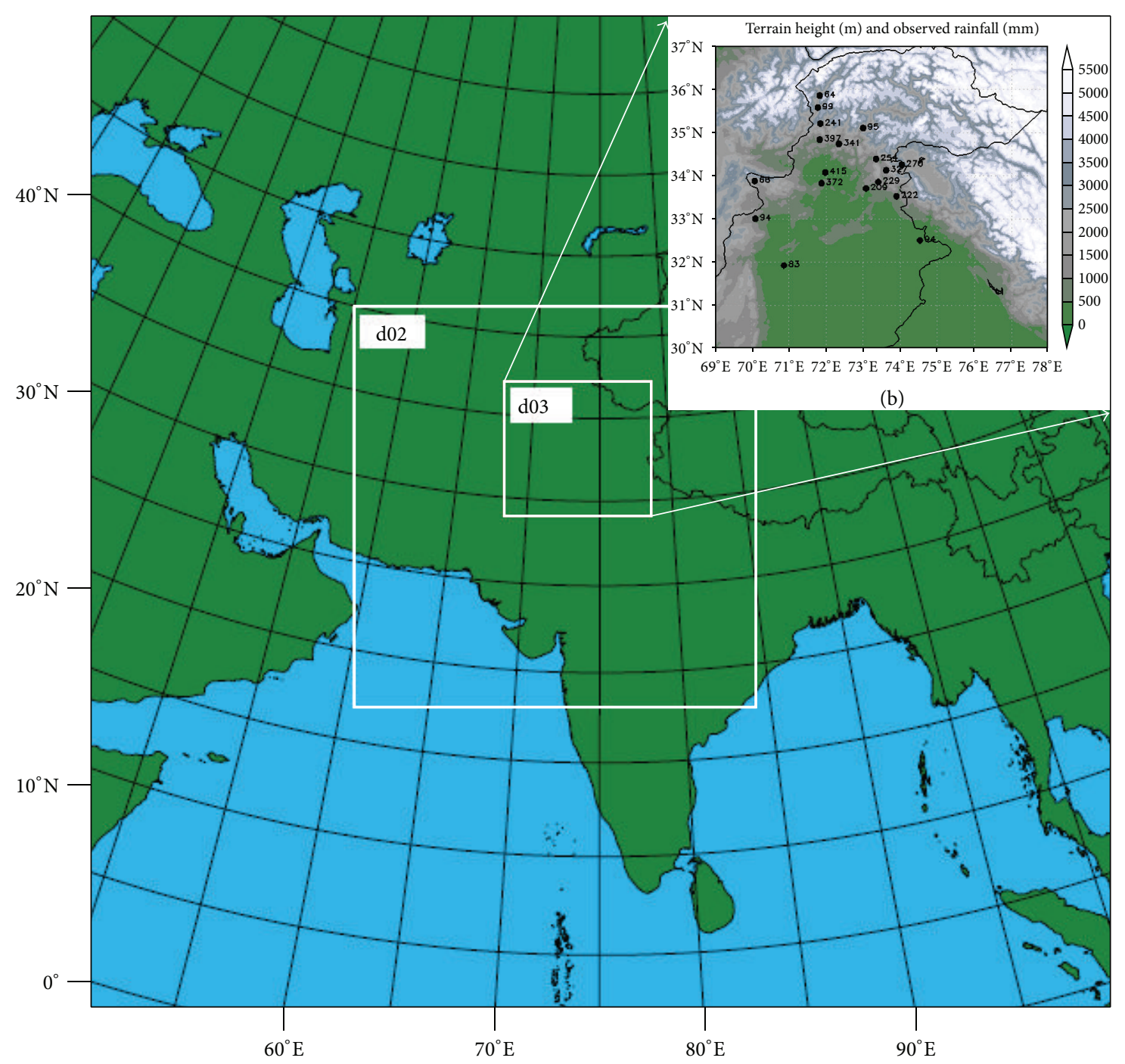

(a)

FIGURE 1: Three nested domains d01, d02, and d03 for WRF simulation. Domain-3 highlighted in the upper right corner indicates (b) terrain height and amount of rainfall observed at the station.

horizontal Smagorinsky were also kept on. Both simulations were performed with the microphysical choices as shown in Table 1.

After determining that CTL case of the model is able to produce the realistic simulation, the LOW case (reduced topography by $50 \%$ ) simulation has been performed to determine the impact of the high terrain on the evolution of the weather system, spatial distribution, and magnitude of the precipitation. The topography is reduced in such a way that original shape of the mountain does not change and topography may not reduce below $1500 \mathrm{~m}$. In LOW case, the same parameterization schemes have been used as discussed above in the CTL case, except the reduction of topography of the region in domain d03. To avoid boundary issues, topography of the same region of $\mathrm{d} 03$ is also reduced over the same area of $\mathrm{d} 02$ and $\mathrm{d} 01$, respectively. The modified topography maintains its original structure and orientation in all the three domains. The initial conditions are interpolated to the modified terrain, but the model characteristics, physics, and other dynamics options are kept unchanged. The simulated rainfall and other meteorological parameters are compared to measure the changes in the rainfall, wind convergence, and geopotential heights. The vertical profile of potential temperature, specific humidity, and heat energy fluxes transfer has also been calculated to measure the thermodynamic impact. The energy transfer measures the changes in the instabilities and resultant convection.

\section{Synoptic and Mesoscale Overview of the Event}

Pakistan is located in the South Asian Monsoon region having Himalaya and Hindukush in " $\mathrm{L}$ " shape orientation in its north as shown in Figure 1(b). Extreme weather events became important phenomenon during the monsoon period due to high unpredictability in catchment areas of this region. 
Orography plays key role in occurrence of monsoon rainfall in this region. The precipitation occurs due to the blockage of the mountains to monsoonal flow and entrainment of moist low level air in the unblocked air aloft.

Pakistan experienced a heavy rainfall event from 26 to 30 July, 2010, in its north parts. The observed area-weighted rainfall in this region, during the monsoon period, is about $222 \mathrm{~mm}$. But during 2010, it received $150 \mathrm{~mm}$ above normal rainfall as shown in Figure 2(b). Most of the precipitation was received during this one particular event. Eleven out of the eighteen stations in the provinces of Khyber Pakhtoon Khawa, Punjab, and AJK observed more than $200 \mathrm{~mm}$ rainfall during this event, as indicated in Figure 2(a). The rainfall measured during this event of July 2010 exceeds the threshold of 50 years of return period. The strong signals of extreme event appear in the form of changes in the tropospheric circulations before its occurrence. In order to determine this, anomaly of the air temperature, wind, and geopotential height from NCEP data for the period 26-30 July, 2010, to mean (1979-2008) reveals that trough at $300 \mathrm{hPa}$ split the high into two, Eurasian and Chinese high.

These anticyclones are exceptionally warm by up to $8^{\circ} \mathrm{C}$ to normal temperatures. In the east, positive anomalies of temperature and geopotential height in upper troposphere inhibit convection and stabilize the atmosphere. It results in the increased warming of the vertical column of the core precipitation region and is responsible for the strengthening of the baroclinic low level high over Tibetan Plateau. The resulting strong pressure gradient causes the increased winds and is responsible for the convergence zone along the foothills of Himalaya, extending up to the core precipitation area in north Pakistan as in Figures 3(b) and 3(c). The low level pressure gradient enhanced moisture flux in the region as shown in Figure 4(a). The eastern high gradually intensified imposingly before event and shifted $10^{\circ}$ east of its climatological mean position as in Figures 4(c) and 4(d). The low level trough further deepened, making hook-like shape along the Hindukush region, and penetrated to lower latitudes in west of Pakistan, bringing cold, drier Siberian air to this region. The seasonal low over Baluchistan province intensified and shifted southward of its normal climatic position. Warming over the north Arabian Sea at lower level results in enhanced evaporation. The increased anticyclonic circulations over the central Punjab bring the enhanced moisture from the Arabian ocean on the face of Himalaya, as shown in Figure 3(c). This enhanced moisture convergence in the mountainous region causes instability and thus initiation of convection. The deep warm core high over Eurasia acted as unusual blocking pattern. It was positioned $10^{\circ}$ degree east of its normal location. The enhanced pressure gradient pushes the elongated cold core towards the middle latitude trough in the west of Hindukush mountain. Due to Eurasia blocking high the attendant low level energy amplifies the trough in the northwest of Pakistan as is evident in Figure 3(c). The mesoscale convection in the high mountainous region was enhanced by the continuous moisture supply in this area. The orography in this region provides the basic uplifting mechanism for the moist air river coming from BoB and Arabian ocean, whereas cold, dry air from the north sets

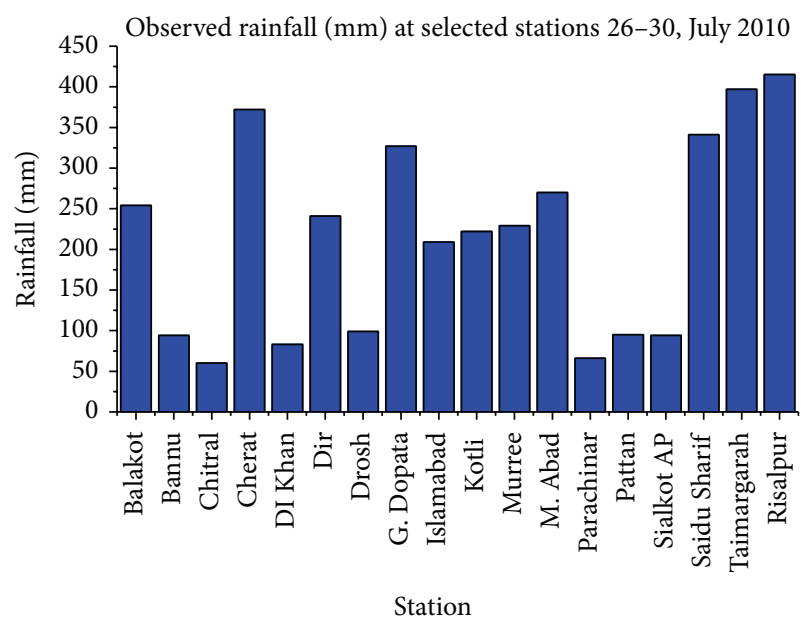

(a)

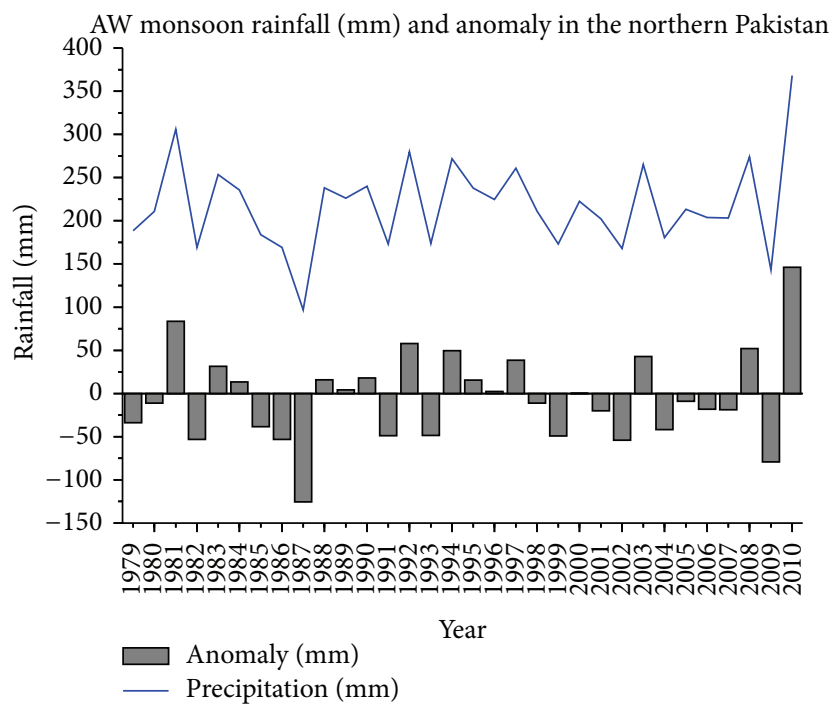

(b)

FIgUre 2: (a) The rainfall amount at the selected 18 observing stations in the north Pakistan, and (b) area weighted monsoon (JJAS) rainfall (blue line) and anomaly (for north Pakistan between $30^{\circ} \mathrm{N}$ and $37^{\circ} \mathrm{N}$ ). Year 2010 indicates the above normal rainfall.

a platform for the enhanced instability and deep convection resulting in growth of heavy precipitation system in the north Pakistan.

The six hourly time-longitude graph of vertical integrated moisture flux in Figure 4 (b) at $34^{\circ} \mathrm{N}$ and $66^{\circ} \mathrm{E}-77^{\circ} \mathrm{E}$ from 1000 to $500 \mathrm{hPa}$ level indicates the heavy rainfall between $70^{\circ} \mathrm{E}$ and $76^{\circ} \mathrm{E}$, during 28-29 July, 2010. The heavy moisture flux is mainly from $\mathrm{BoB}$ and the Arabian ocean and from a conveyor belt-like situation as in Figure 4(a). The moisture accumulation near mountains increases the moist instability and convection potential in the region. It is confined by the strong temperature inversion over the north Pakistan as evident from Figures 3(a)-3(c). Such an extension of relatively cold, dry air in west and steep mountains inclinations to persistent moist flow provides the large scale structure, favorable for development of warm core MTCs [56]. The moist 
Anomaly of air temperature $\left({ }^{\circ} \mathrm{C}\right)$, wind $(\mathrm{m} / \mathrm{s})$, and gpm height (300 hPa), 26-30 July, 2010, to average 1979-2010

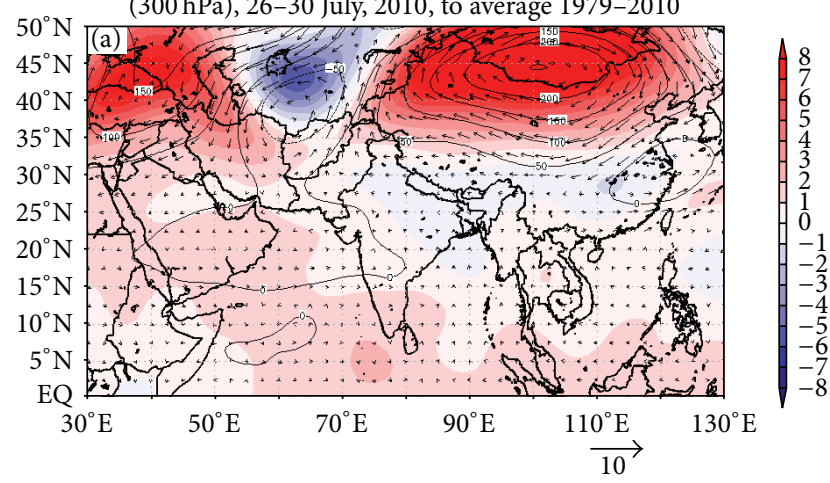

(a)

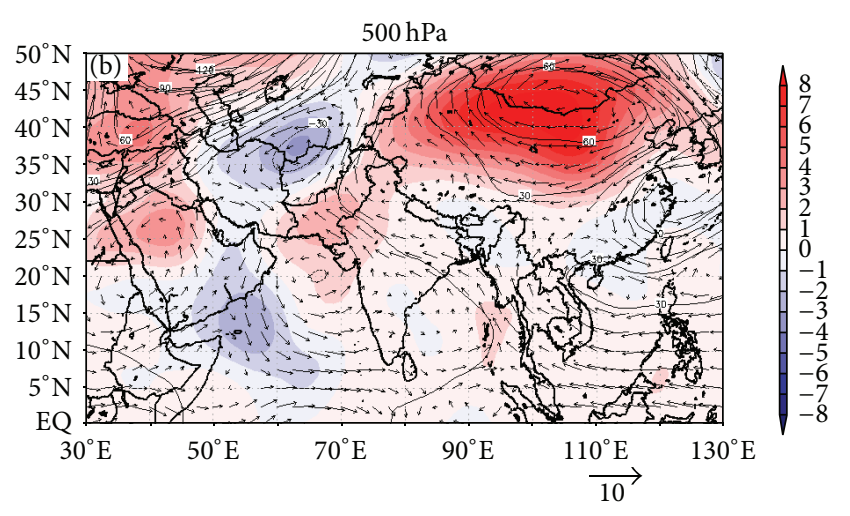

(b)

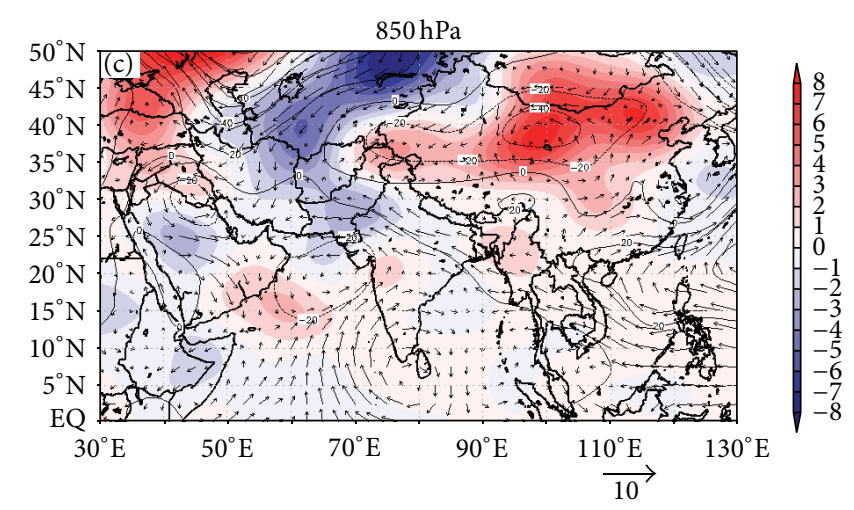

(c)

Figure 3: Five days average, from 26 to 30 July, 2010, of air temperature, wind, and geopotential height anomaly calculated from the NCEP/NCAR data at (a) $850 \mathrm{hPa}$, (b) $500 \mathrm{hPa}$, and (c) $300 \mathrm{hPa}$. A profound trough split the normal high in two warm core highs, with its hook shape edge at the north Pakistan.

flow condenses and releases latent heat resulting in increase in instability. The latent heat and updrafts provide positive feedback for increased moisture flow consequence into deep convection in the region.

The seasonal heating over Tibetan Plateau being the heat source causes reversal of meridional temperature and pressure gradient along the Himalaya foothills. It results in triggering large scale changes in the general circulation over Asia and monsoon heavy rainfall over South Asia. Figures 4(c) and 4(d) reveal that Tibetan High was very strong just before the incidence of this extreme precipitation event and its center was moving between $30^{\circ} \mathrm{N}$ and $40^{\circ} \mathrm{N}$. In South Asian Monsoon, warming of Tibetan Plateau than the Himalaya causes northward shifting of ITCZ resulting in heavy rainfall, as occurred in this event.

To monitor the system, three PMD observation stations of Kotli, Islamabad, and Saidu Sharif were selected and time series of temperature, dew point temperature, relative humidity, and rainfall has been drawn, for the period of 2630 July, 2010 (Figures 5(a)-5(d)). The temperature at these stations rises significantly by $8-10^{\circ} \mathrm{C}$ on 26 July and enhances the moisture holding capacity of atmosphere. It exponentially increases the saturation vapor pressure and hence the relative humidity decreases considerably. The persistent moisture flow filled in the gap as in Figures 4(a) and 4(b). The drop in air temperature initiates the condensation process and increases in relative humidity. Dew point temperature and air temperature became equal at 0000 UTC of 27 July, and the relative humidity exceeds $90 \%$. The topography provides the primary triggering mechanism for rainfall. The rain first started at Kotli and gradually moved westward to Islamabad located in foothills of Himalaya and Saidu Sharif in the Hindukush region. This system produced a wide spread heavy rainfall in the region as indicated in Figure 1(b). Taimargarah and Risalpur received the maximum rainfall of above $400 \mathrm{~mm}$ during this episode.

\section{Model Results}

WRF model coupled with Morrison double moment scheme with three nested domains is used to simulate the heavy rainfall event of 26-30 July, 2010. Two sensitivity tests, with full topography (CTL) and reduced topography by $50 \%$ (LOW), were designed to investigate the topographic impact on the evolution of this event. The CTL case is verified by comparing its results to NOAA CIRES reanalysis data outcomes. The WRF outcomes for temperature, geopotential height, wind vector, and relative humidity at 


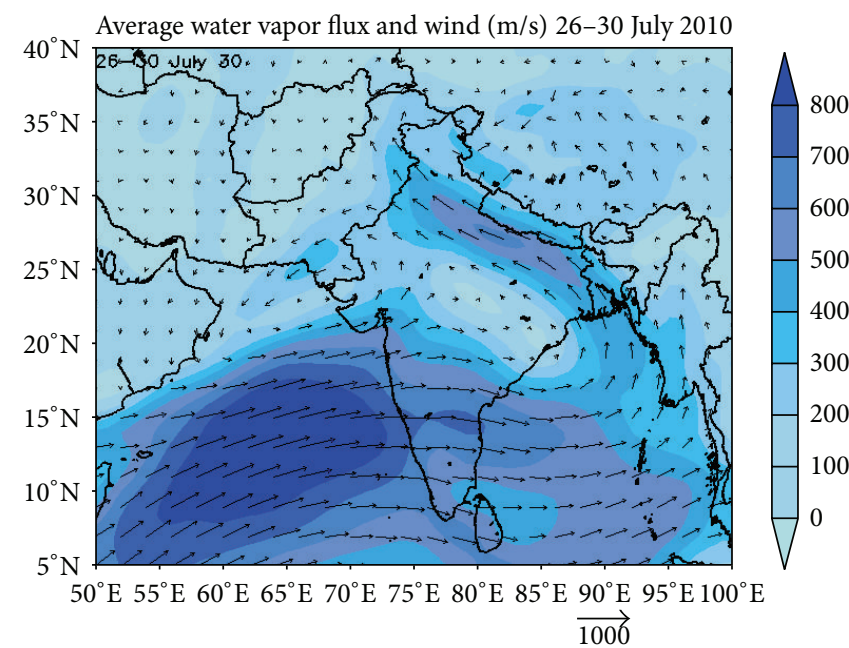

(a)

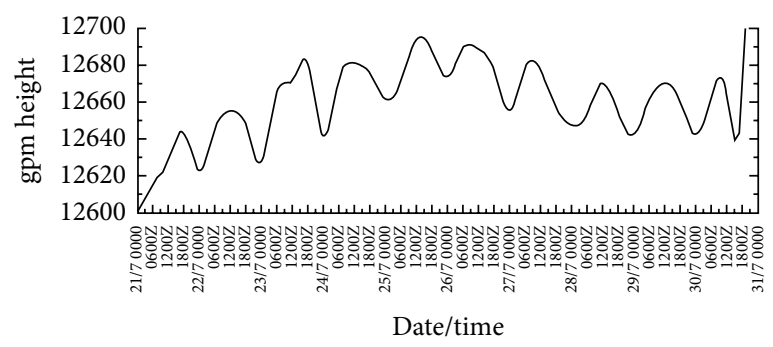

(c)

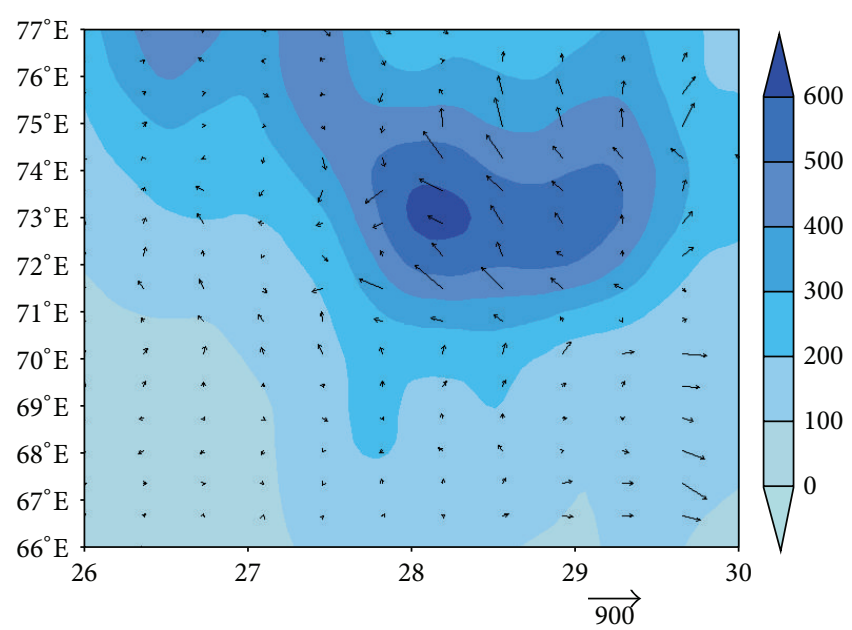

(b)

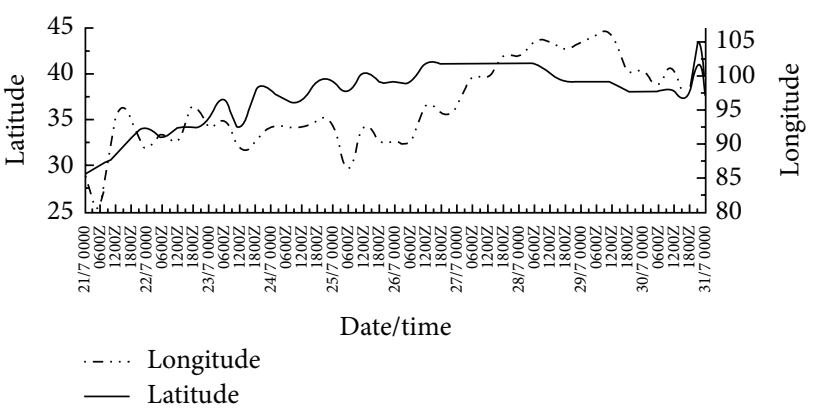

(d)

FIGURE 4: (a) Vertically integrated moisture flux and winds between $1000 \mathrm{hPa}$ and $500 \mathrm{hPa}$, (b) longitude-time graph of moisture flux between $32^{\circ}$ and $35^{\circ} \mathrm{N}$ from 26 to 30 July, (c) time series of geopotential height at $200 \mathrm{hPa}$, and (d) location of the center of the Tibetan High during the period of 21-31 July, 2010.

different pressure level (Figures 6(a)-6(d)) showed the good correlation with reanalysis data outputs (Figures $6(\mathrm{e})-6(\mathrm{~h})$ ).

The heavy precipitation occurs, when rainfall frequency is higher for longer span of time [57]. The depression from the $\mathrm{BoB}$ is embedded in a mesoscale system which has been observed at lower levels indicating tropospheric flow towards NW parts of Pakistan. A strong pressure gradient is fairly visible along foothills of Himalaya, indicating strengthening of seasonal trough over India and its northward movement. It results in bringing the moisture flow along Himalaya foothills in the north Pakistan. The seasonal low over Baluchistan shifted southward and took the north-south orientation, resulting in additional moist flow from the Arabian Sea on the face of Himalaya. The strong moist flow, impinging over the mountain, Advected higher in the atmosphere and causes convective rain. The rain rate is proportional to continuous supply of vertical moisture flux and ascent velocity over the mountains slope. The spatial scale of big mountain range in this area and microphysical time scale plays a critical role in the particle growth.

4.1. Evolution of the Precipitation Feature. In stable flow approaching a mountain barrier, the response of the flow to the terrain height depends on three basic factors: the strength of the cross barrier component of the flow, height of terrain barrier, and thermodynamic stability of the incoming flow.

The cumulative ground precipitation, wind $(950 \mathrm{hPa})$, and geopotential height $(500 \mathrm{hPa})$ for the CTL case (Figures $7(\mathrm{a})-7(\mathrm{~d}))$ and for LOW case in Figures $7(\mathrm{e})-7(\mathrm{~h})$ reveal the quantitative, temporal, and spatial distribution of rainfall. In CTL case, two distinct precipitation features were identified, as Hindukush precipitation zone (HkPZ) located in northwest over Hindukush and Himalayan precipitation zone (HmPZ) over and along the foothills of the Himalayan mountain (Figure 7(d)). The structure of these features is associated with the topography, zonal circulations, and wind fields. At the beginning of CTL simulation, wind flow from $\mathrm{BoB}$ is prominent along Himalayan foothills, directly on the face of Hindukush mountains producing major rainfall in this region. Initially, a northeast oriented rain region formed over Hindukush along the western borders of Pakistan. HkPZ got intensified with the evolution of time and is spatially distributed between $34^{\circ} \mathrm{N}$ and $36^{\circ} \mathrm{N}$.

The anticyclonic circulation formed over central Punjab at 0000 UTC of 29 July and changed the orientation of wind flow mainly from the Arabian Sea. The river of the warm moist air along the Himalaya is coming into the region. The huge convection over the upslope of the mountain 


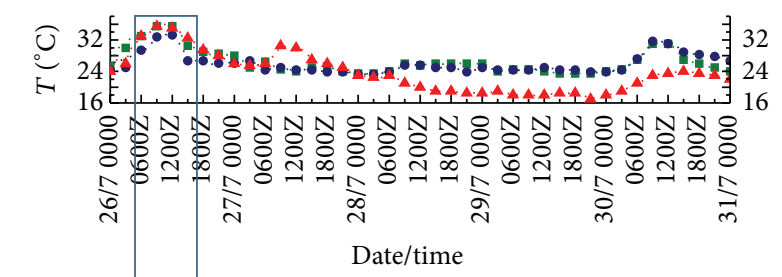

(a)

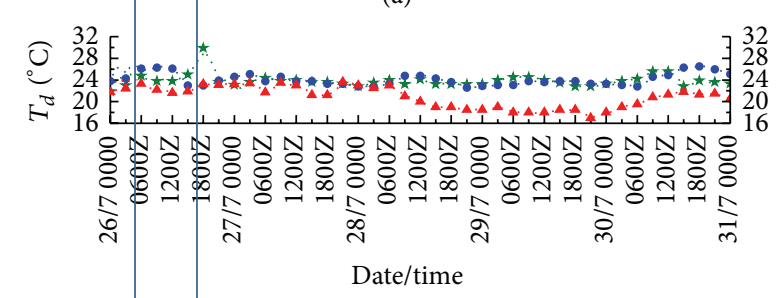

(b)
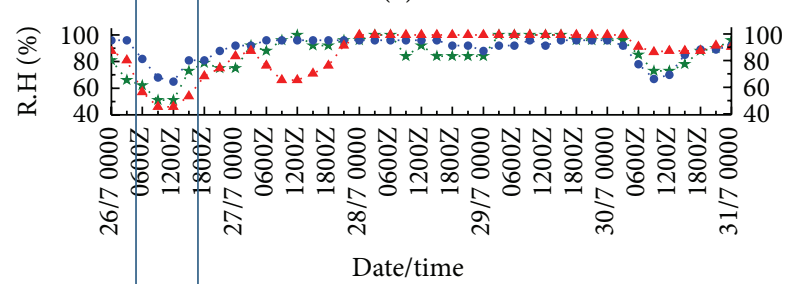

(c)

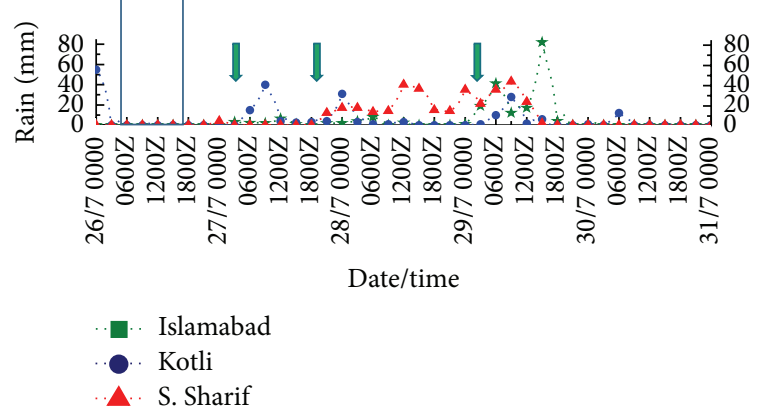

(d)

Figure 5: Time series of (a) temperature $\left({ }^{\circ} \mathrm{C}\right)$, (b) dew point temperature $\left({ }^{\circ} \mathrm{C}\right)$, and $(\mathrm{c})$ relative humidity $(\%)$ at Kotli, Islamabad, and Saidu Sharif during 26-31 July, 2010.

occurred when the intense moist circulation intersected a steep Himalayan barrier which results in enhanced precipitation in HmPZ. The secondary precipitation zone formed along the Himalaya foothills and gradually deepened and merged with HmPZ at 0600 UTC of 28 July. The low level static stability allows the incoming moist air to rise over terrain and produced mesoscale convective systems giving stratiform precipitation regions, even on planes along this region, as can be seen in foothills of Himalaya. The two precipitation zones gradually intensified with time and their schematic features are marked in Figures 7(a)-7(d).

The trough in the northwest of Pakistan causes interaction of cold dry air mass from middle latitude to warmer and convectively unstable monsoon air mass in the region at middle upper troposphere level and provides triggering to severe weather system (Figures $8(\mathrm{a})-8(\mathrm{~d})$ ). The warm moist flow at lower level and cold advection at upper level produce the strong convective instability in the vertical column of the atmosphere. The continuous moisture supply stimulated throughout the development process, under the prevailing conditions, gives rise to intense weather system. The orography (mechanical forcing) provided the triggering mechanism to augmentation of these heavy precipitation features on the windward side of the two mountain ranges. The average height of the Himalaya is far higher than Hindukush mountains.

In LOW case, reduction of the topography allows the mid latitude dry, cold trough to overrun the Hindukush region (Figures $7(\mathrm{e})$ and $7(\mathrm{f})$ ). The area gets neither the magnitude nor the heavy precipitation in the HkPZ, but rather it disappeared in LOW case. It indicates that after reduction the topographic height in the Hindukush region is not sufficient to provide the triggering mechanism for orographic precipitation in this region. This deformation appears by the weakening of the turning effect from mountain barrier. The spatial distribution of rainfall varied remarkably in the $\mathrm{HmPZ}$ and rain area deepens over Himalayan region along the NE border of Pakistan. The orientation of anticyclonic circulation formed over central Punjab changed significantly resulting in accumulation of moisture currents from $\mathrm{BoB}$ and the Arabian Sea into Himalayan foothills. The rainfall intensity over HmPZ increases as the barrier jet increases the convection over the slope (Figures $7(\mathrm{~g})$ and $7(\mathrm{~h})$ ). The orographic slope in Himalaya uplifted incoming warm moist air flow produces the vigorous clouds growth. It is due to the fact that bulk lifting weakens the subsidence warming in the unsaturated downdrafts and increases the latent heat release within the updraft. The raindrops in this situation grow faster due to the buoyant updrafts which resulted in heavy downpour in the region.

4.2. Comparison of Wind Divergence and Trajectory Analysis. The wind divergence field at $850 \mathrm{hPa}$ for the CTL case (Figures $8(\mathrm{a})-8(\mathrm{~d})$ ) simulation indicates a well-defined low level convergence, between $71^{\circ} \mathrm{E}-73^{\circ} \mathrm{E}$ and $34^{\circ} \mathrm{N}-35^{\circ} \mathrm{N}$ across the Hindukush mountain barrier at 1200 UTC of 28 July. It can be seen that vertically propagating wave motion was produced over this high mountainous region, inclined upward and upstream. The wind convergence along the Himalaya foothills gradually intensified on formation of low level anticyclonic circulation bringing consistent flow from the Arabian Sea to the slopes of Himalaya mountain. This change is quite visible in following time steps on 28-29 July in the CTL case. The maximum convergence zone at HkPZ and $\mathrm{HmPZ}$ corresponds well to location and timing of the higher precipitation zones in both the cases. This low level convergence is an evidence of barrier jets that formed due to big Himalayan and Hindukush mountain regions. The synoptic scale flow over a region of large mountains can create a line of moisture convergence and trigger convection. Such a flow is enhanced by the diurnal heating or by gravity waves over the terrain $[58,59]$.

In LOW case, the strongest low level convergence is centered deep over Himalaya. The convergence in this region was greatest on 0600 UTC of 29 July. The low level convergence is completely missing over the Hindukush in HkPZ. It appears 
T, UV, gpm (500 hPa), 28 July (1200 UTC)

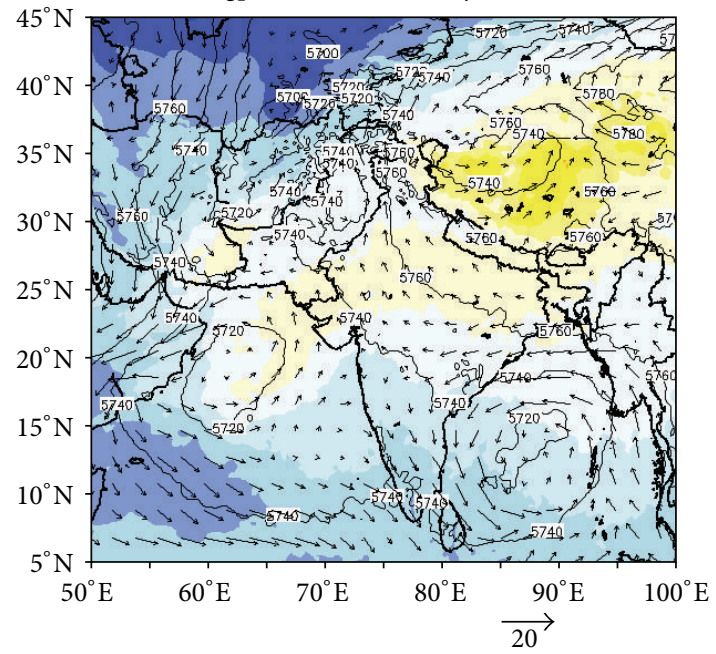

(a)

T, UV, gpm (500 hPa), 28 July (1800 UTC)

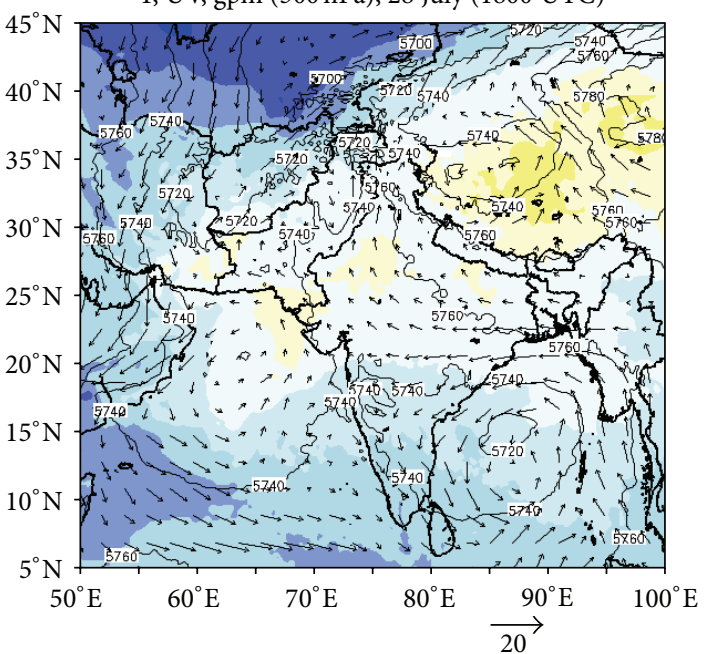

(b)

T, UV, gpm (500 hPa), 29 July (0000 UTC)

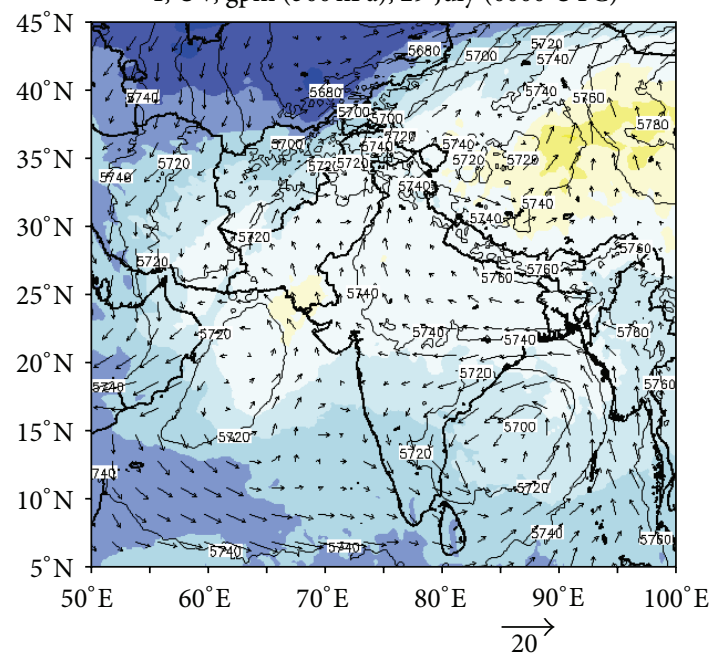

(c)
T, UV, gpm (500 hPa), 28 July (1200 UTC)

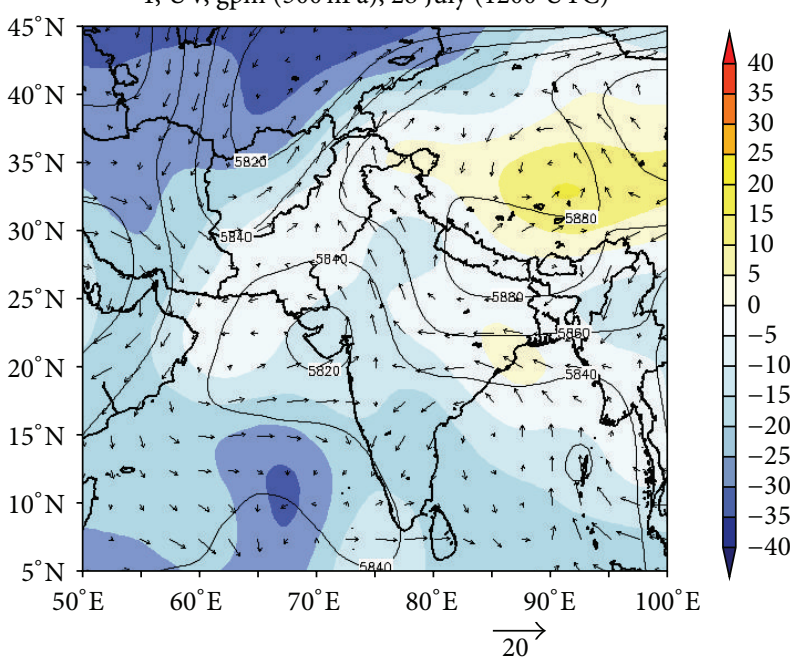

(e)

T, UV, gpm (500 hPa), 28 July (1800 UTC)

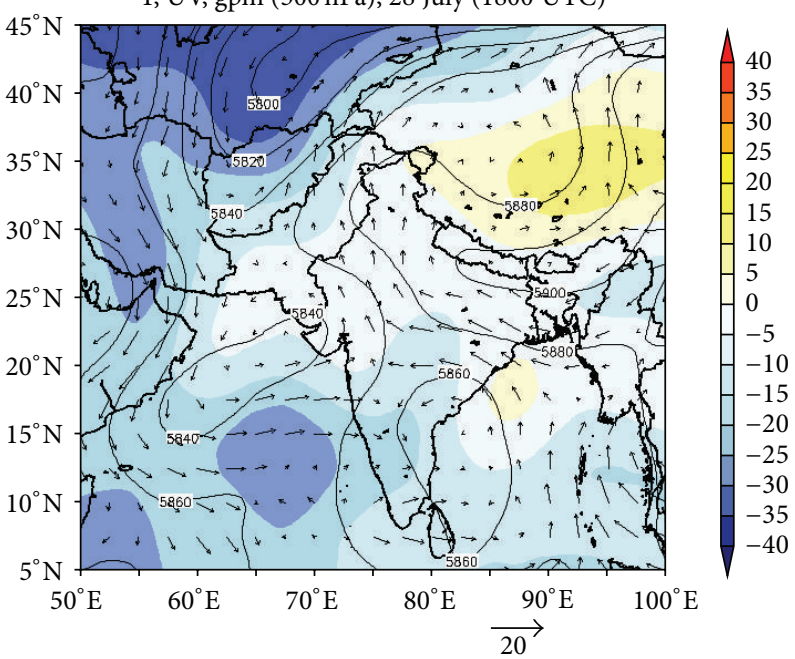

(f)

T, UV, gpm (500 hPa), 29 July (0000 UTC)

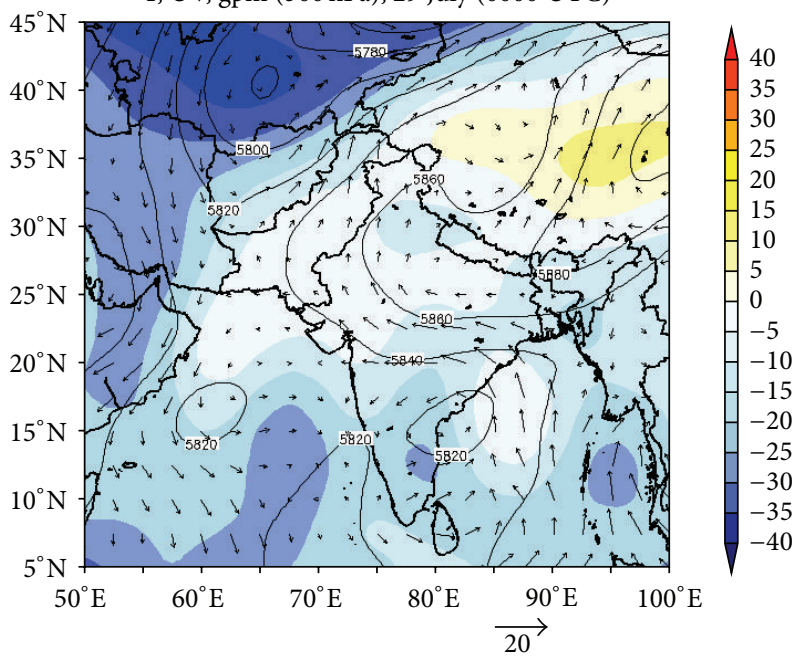

(g)

FIGURE 6: Continued. 


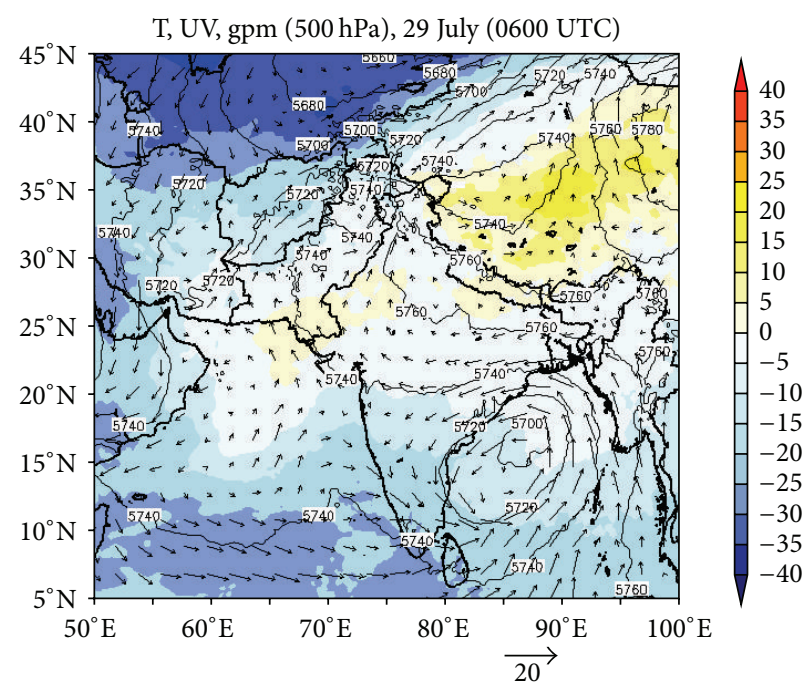

(d)

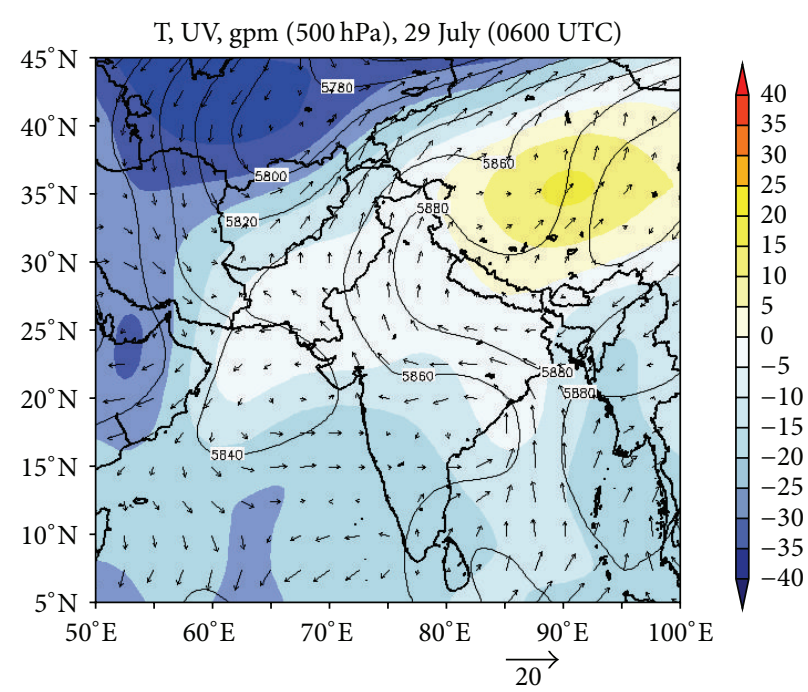

(h)

Figure 6: Comparison of the temperature $\left({ }^{\circ} \mathrm{C}\right)$, geopotential height, and wind vector $(500 \mathrm{hPa})$ of (a) WRF CTL output (left pane) and (b) NCEP/NCAR reanalysis data (right pane) at different time steps.

that, after reducing the topography, the height of Hindukush mountain is insufficient to provide the lifting to the moist monsoon airmass flow.

The vertical temperature and moisture profile in a weather system controls the microphysical species in the clouds. The latitude-height cross section along the $73^{\circ} \mathrm{E}$ longitude in Figure 9 indicates the turbulent easterly flow (upto $10 \mathrm{msec}^{-1}$ ) on the windward side of the Himalaya over Islamabad $\left(33^{\circ} \mathrm{N}\right.$ and $\left.35^{\circ} \mathrm{N}\right)$ and the adjacent areas. This turbulent layer plays a crucial role for enhancing the growth of the precipitation particles and thus speeding up their fallout on the windward side. The wind maxima of easterly flow correspond in both timing and location to that of the heavy precipitation intensity area (Figure 7 ) and vertically extended up to $600 \mathrm{hPa}$ as in Figure 9. The streamlines indicate the zonal wind flow carrying the moisture from the Arabian Sea to this region. The gradient of specific humidity maximum ( $>19 \mathrm{~g} / \mathrm{kg}$ ) was observed in the Himalayan foothills, indicating the availability of huge moisture transported from tropics to the face of big mountainous barrier. The overwhelming of deep unstable air mass on the windward slopes of the mountain is lifted above LFC, yielding convective clouds and precipitation. The precipitation in $\mathrm{HmPZ}$ and $\mathrm{HkPZ}$ is based on their respective level of the instability. It has been revealed that cross barrier flow structure documented over the windward cascade slopes differs appreciably from the case of profoundly blocked flow, observed adjacent to taller mountain ranges [60-62]. The propagating mesoscale convective system can also stall at the edge of the blocked layer and in front of the mountain range, as has happened in this case yielding a wide spread rainfall along the Himalayan foothills.

To identify the moist air mass source region and diagnose the forcing for convective precipitation, three-dimensional advection techniques were used to draw the 24-hour backward (blue) and forward (red) trajectories for both CTL and
LOW cases at all model levels at $73^{\circ} \mathrm{E}$ and $33.5^{\circ} \mathrm{N}$ (Islamabad) as in Figures 10(a) and 10(b). In CTL case, air parcels below $500 \mathrm{hPa}$ turn to $\mathrm{HkPZ}$ under the influence of southeasterly wind flow. However, ascending air over HmPZ condenses due to orographic lifting and yields heavy precipitation in the region. It is believed that easterly barrier flow produced due to terrain features on the windward side is acting as a transport mechanism for the incoming moist air parcels deep in the $\mathrm{HmPZ}$. However, air above $500 \mathrm{hPa}$ followed the prevailing mid and upper level flow.

In LOW case, air parcel below $700 \mathrm{hPa}$ over Himalaya is blocked by the topography and reduction in topography resulted in significant difference in the spatial and quantitative distribution of precipitation (Figure 10(b)). The main differences are the broadening and intensification of the precipitation zone over HmPZ. It may be due to the fact that average height of $\mathrm{HmPZ}$ is enough even after reduction of topography by half, to provide the forcing for precipitation. The trajectory analysis indicates that the air above $3000 \mathrm{~m}$ follows the synoptic flow. A similar study was done by Garvert et al. [63], and our findings are coherent with them. The precipitation difference between two simulations directly relates to topography; the easterly jet along the Himalaya increases convergence and thus producing heavier precipitation.

4.3. Instabilities in the Atmosphere. The vertical profile of vorticity, convective available potential energy (CAPE), and moisture flux for both CTL and LOW cases at $73^{\circ} \mathrm{E}$ has been drawn. CAPE is used to quantify the ambient instability and potential buoyancy of the atmosphere and is considered necessary for the surface based moist convection. In control case, CAPE has the vertical extension up to $600 \mathrm{hPa}$ and is highest near the ground. Its intensity increases temporally and is maximum $(1200 \mathrm{~J} / \mathrm{kg})$ at $0000 \mathrm{UTC}$ and $2000(\mathrm{~J} / \mathrm{kg})$ at 0600 UTC on 29 July (Figures 11(a)-11(d)). It increases the instability in the region and makes the condition favorable 


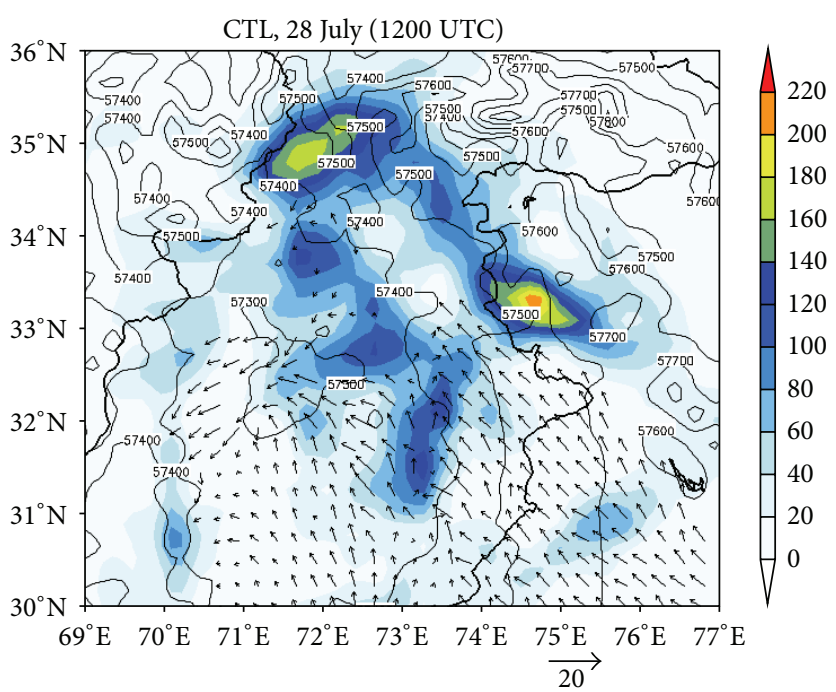

(a)

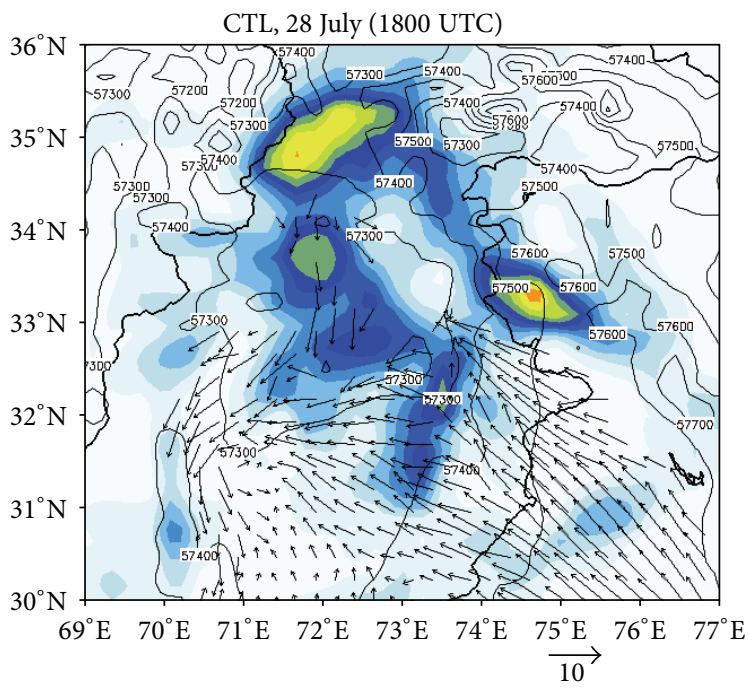

(b)

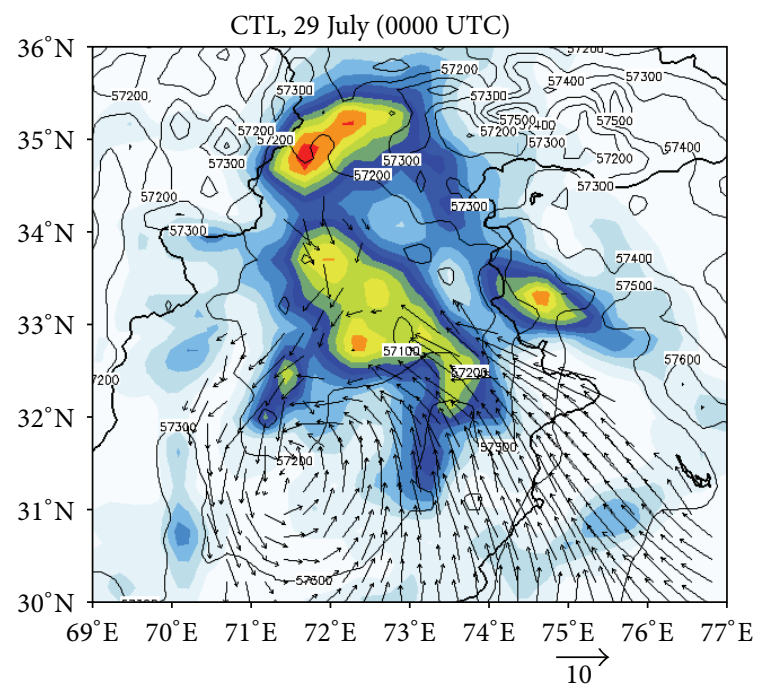

(c)

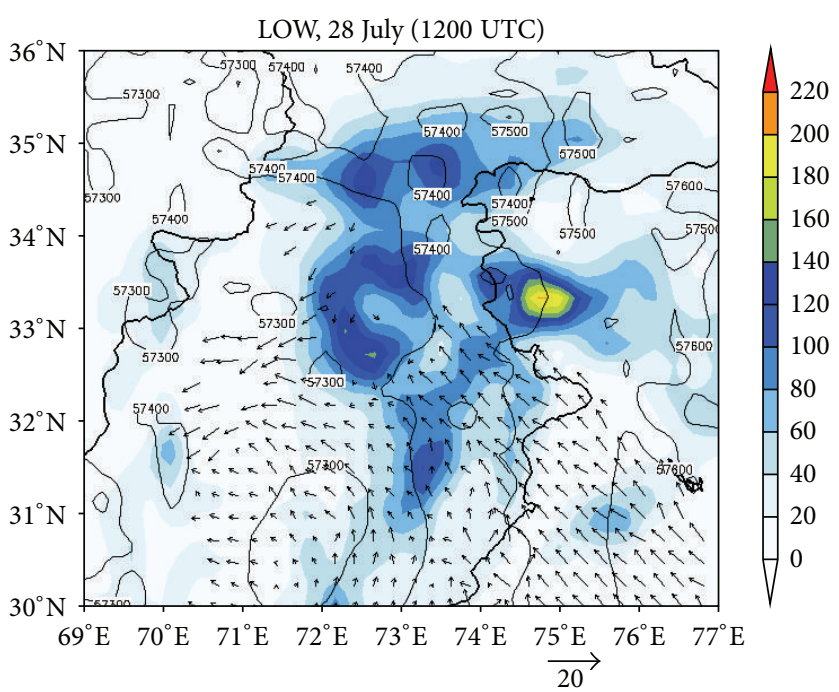

(e)

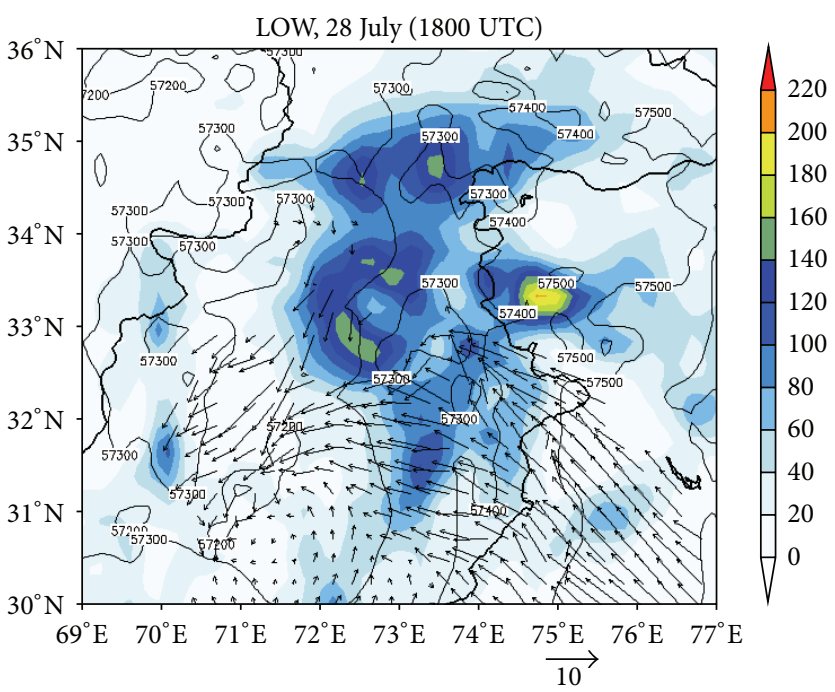

(f)

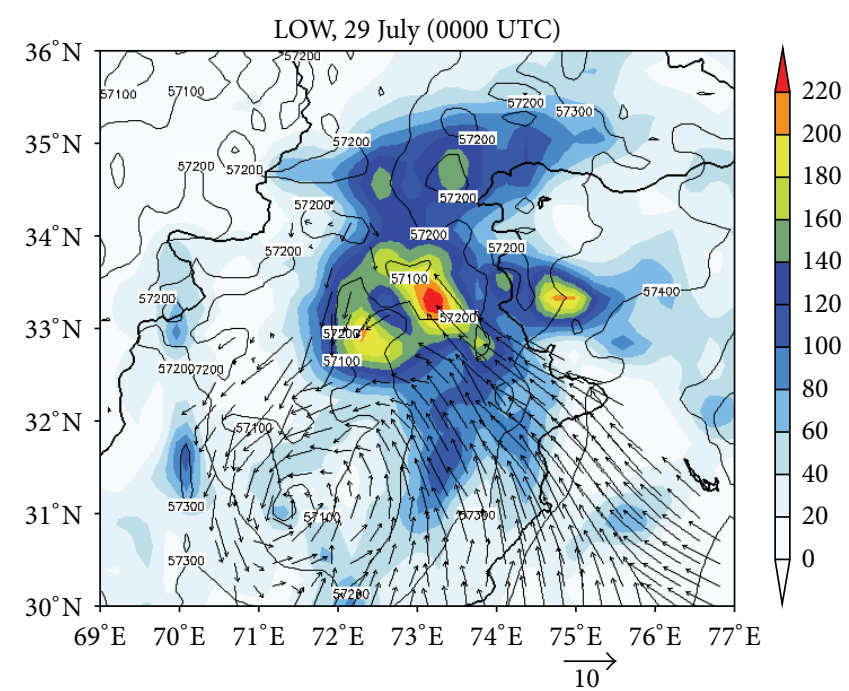

(g)

Figure 7: Continued. 


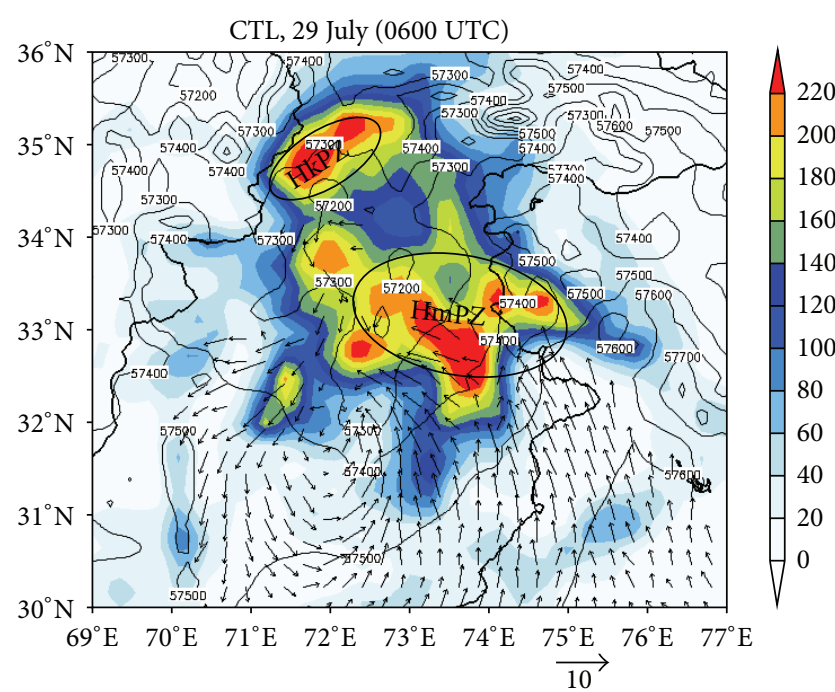

(d)

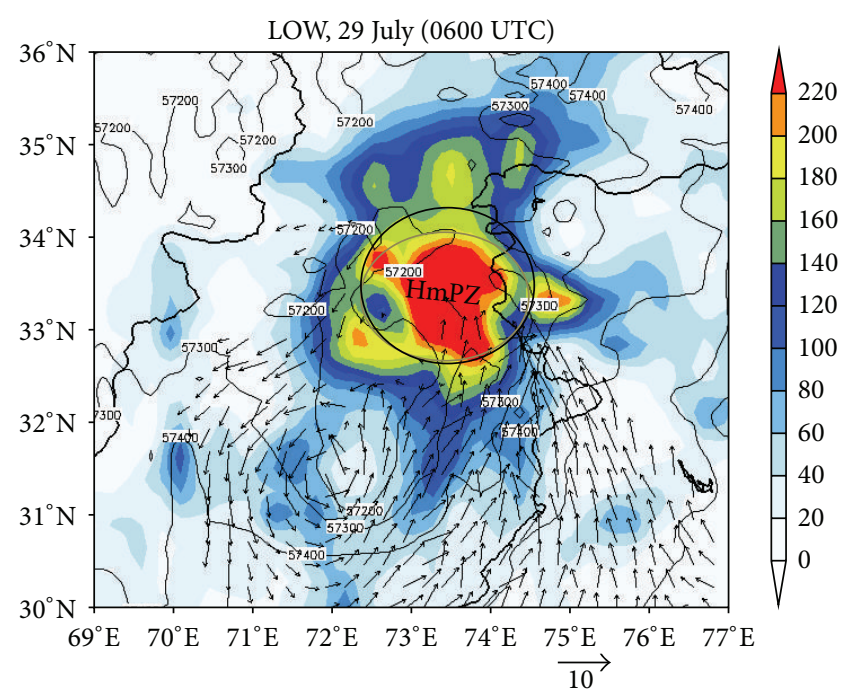

(h)

FIGURE 7: Temporal evolution of precipitation (in $\mathrm{mm}$ ), wind $950 \mathrm{hPa}$, and geopotential height at $500 \mathrm{hPa}$ in ((a)-(d)) CTL case and ((e)-(h)) LOW case. The two precipitation zones are marked as Hindukush precipitation zone (HkPZ) over Hindukush mountains and Himalayan precipitation zone (HmPZ) located in Himalaya mountains.

for huge convection. The strongest low level convergence occurs in the Himalaya foothills due to the influx of the moist unstable air in this region. The vorticity that supported the mesoscale convective system also increases in this area (Figure 11(c)), where primary upward forcing to the moist warm and unstable monsoon airmass is provided by mechanical lifting (i.e., the slope of the Himalayan mountains). The heaviest precipitation region coincides with the area of intense convection in the Himalaya region, as can be seen in Figures $7(a)-7(d)$.

The significant reduction in strength of currents density was noted with low moisture and low CAPE conditions in LOW case. The change in temporal and spatial distribution of CAPE and moisture flux indicates less instability in LOW case, as compared to CTL case. The increased instability over lower latitudes and Himalaya foothills was observed and CAPE was noted as $1200 \mathrm{~J} / \mathrm{Kg}$ at $0600 \mathrm{UTC}$ on 29 July (Figures 11(e)-11(h)). It may be noted that after reducing the topography in this region the warm moist flow moves deep over the Himalaya mountains. The upward forcing is provided by the reduced topography, as these mountains are sufficiently high after reducing by half, to produce tall convection. The vorticity was observed between $32^{\circ} \mathrm{N}$ and $34^{\circ} \mathrm{N}$, where it produced the significant rainfall in the LOW simulation. In summary, the triggering and instability in this region is not built up by the mesoscale convection. The moist air flow from the southeast travelling across the warm desert in lower Pakistan increases its temperature due to surface sensible heating from below and later by latent heating when the parcel moves across the Himalaya mountains. The CAPE indicating enhanced instability was highest in the Himalayan foothills. The orography lifted the flow to produce the initial clouds that blossomed in the mesoscale convective cores resulting in convective precipitation in this region. The reduction in topography causes the lower convective instability over the Himalayan region. Higher the mountain, cloud water content would be greater at the lower level and humidity factor combining with other microphysical and dynamical properties yield in higher precipitation than the shallower features. It affects both the rate and spatial distribution of the precipitation on ground.

Lin et al. [28] found that extremely heavy rainfall occurs when persistent warm moist air layer, moving across the mountain for a substantial time, forms a low level jet due to steep terrain. Since the height of Himalaya is still significant after its reduction, hence it does not affect much the ice concentration in this region.

4.4. Energy and Heat Fluxes. The ability of the air to carry water vapor is of fundamental importance in orographic precipitation. The dynamic response of the airflow to the orography as a lower boundary condition plays an important role in defining the mechanism of hydrometeor growth, advection, and possible evaporation due to latent heat release. It is also known that precipitation distribution is often different for wide and narrow barriers [64]. Turbulent tumbling occurs, when air is blocked at lower level and overridden by strong cross barrier, caused by dynamic instability. This updraft in the layer may produce pockets of locally higher liquid water content and its intensity and position is very sensitive to the terrain height.

In order to determine the impact of energy fluxes on the activities of the subsynoptic scale disturbances and formation of mesoscale convection, eddy kinetic energy (EKE) has been at $500 \mathrm{hPa}$ for both CTL and LOW cases (Figures 12(a) and 12(b)). EKE is computed for the core rainfall time steps to the average of time mean value determined for the simulation period. It has been revealed that EKE have the vast extension over the Himalayan and Hindukush regions in the CTL case and travel across the mountain barriers, indicating the 
CTL, 28 July (1200 UTC)

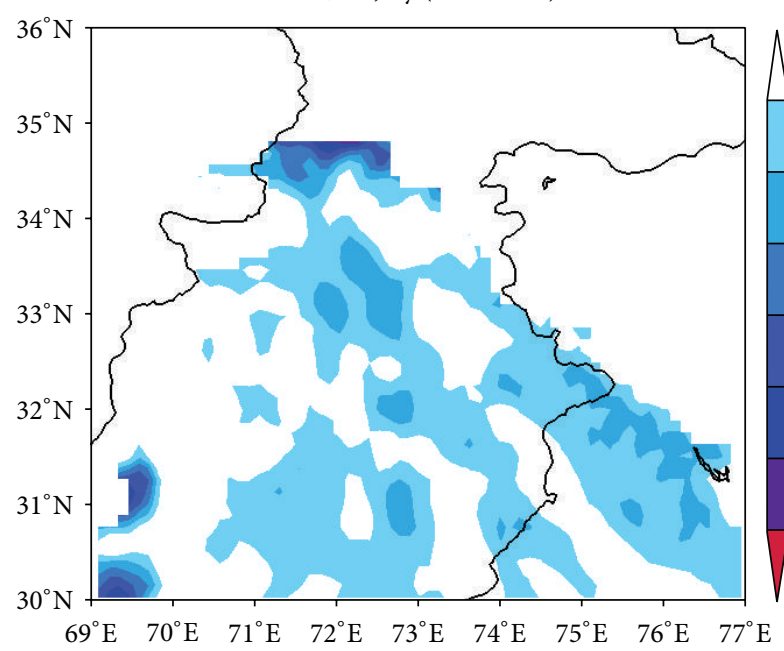

(a)

CTL, 28 July (1800 UTC)

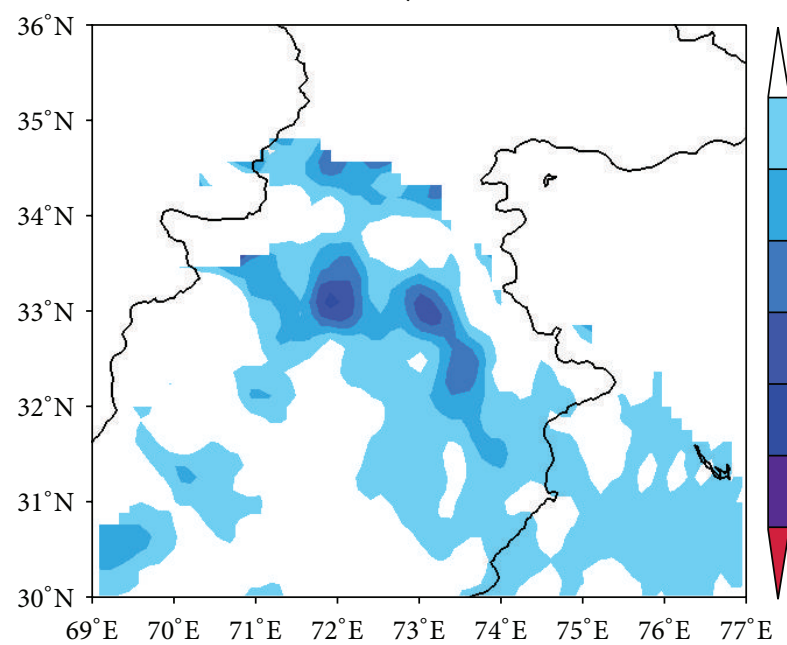

(b)

CTL, 29 July (0000 UTC)

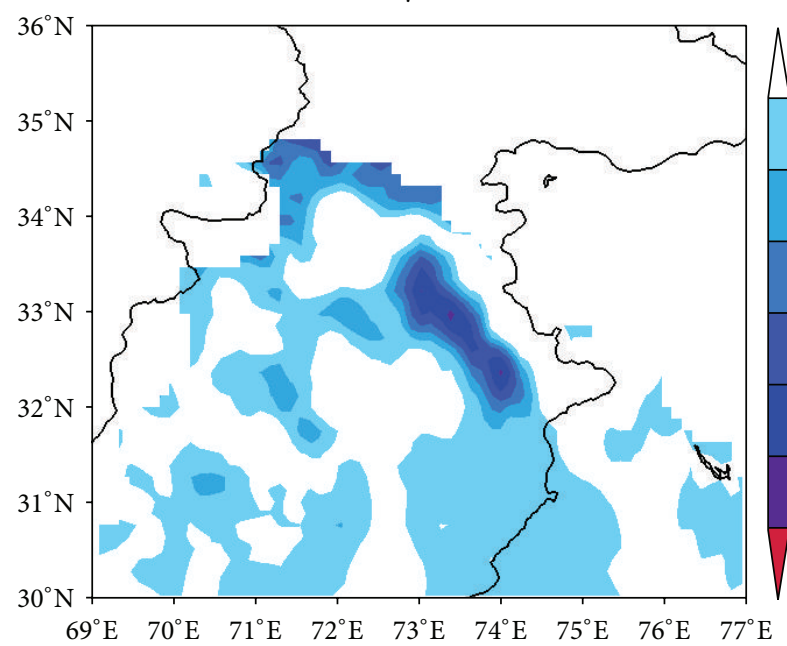

(c)
LOW, 28 July (1200 UTC)

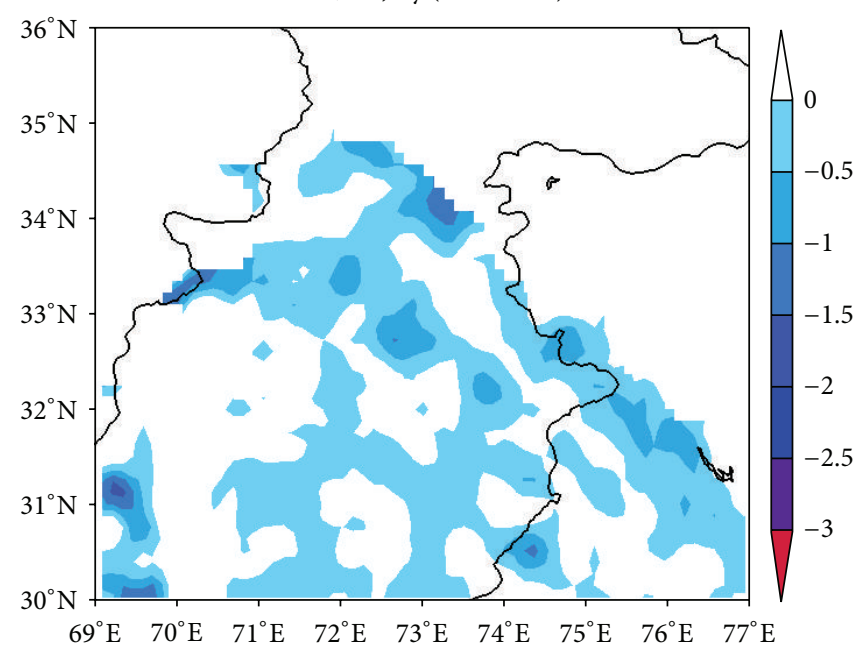

(e)

LOW, 28 July (1800 UTC)

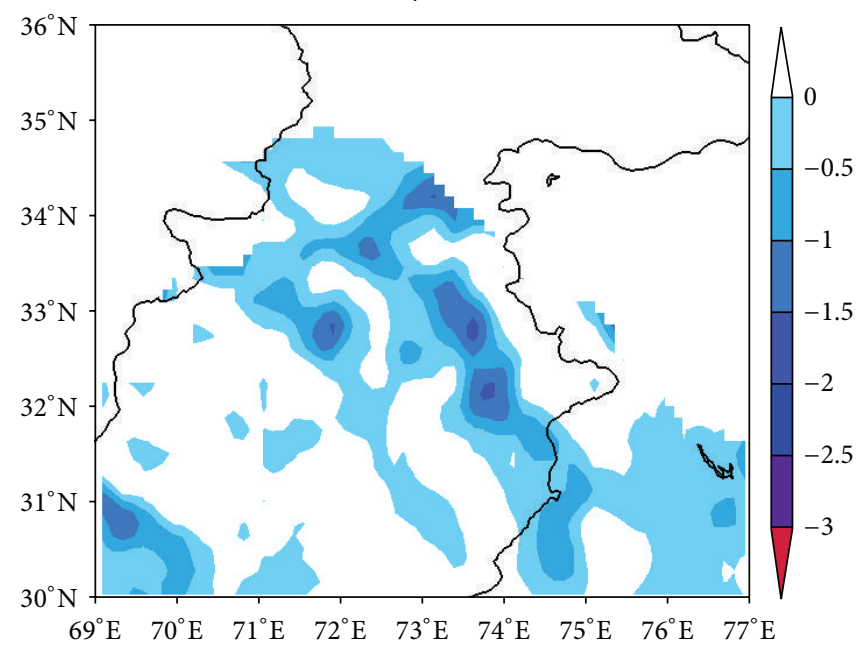

(f)

LOW, 29 July (0000 UTC)

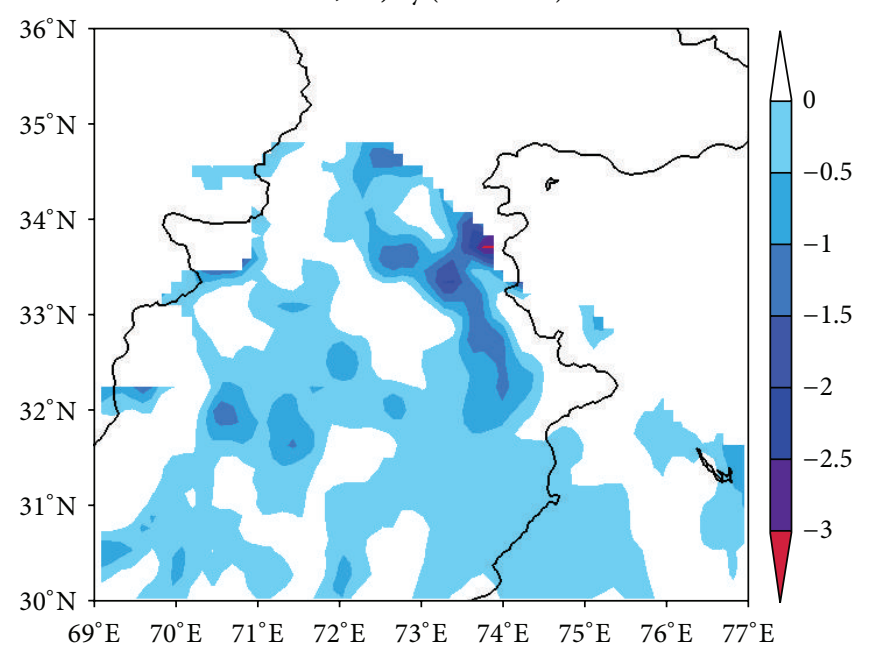

(g)

Figure 8: Continued. 


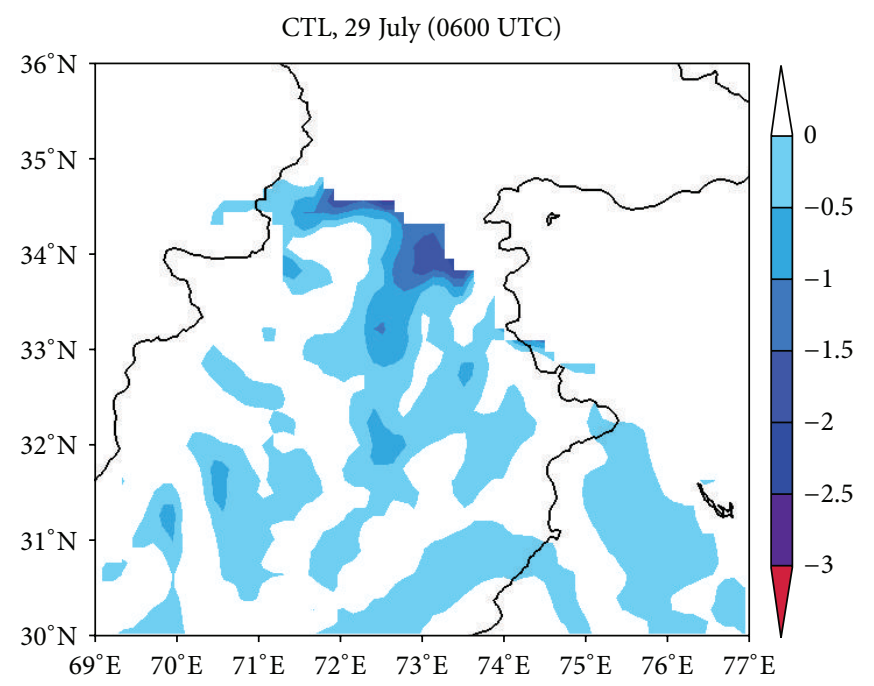

(d)

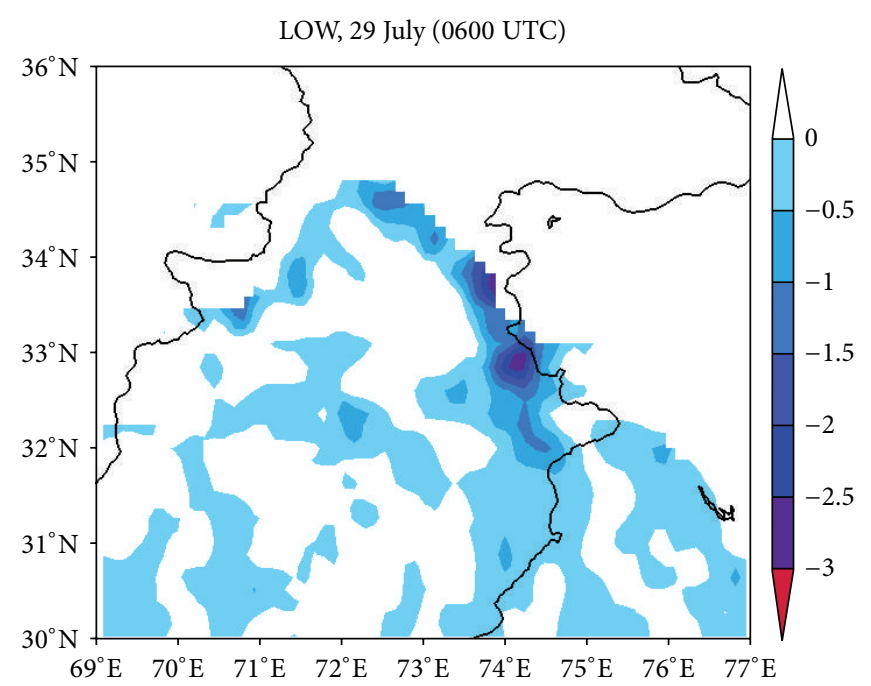

(h)

FIGURE 8: Time evolution of wind divergence $\left(\mathrm{s}^{-1}\right)$ in $((\mathrm{a})-(\mathrm{d}))$ CTL and $((\mathrm{e})-(\mathrm{h}))$ LOW simulations, at 850 hPa. Negative values indicate the convergence area and follow the marked precipitation zones.

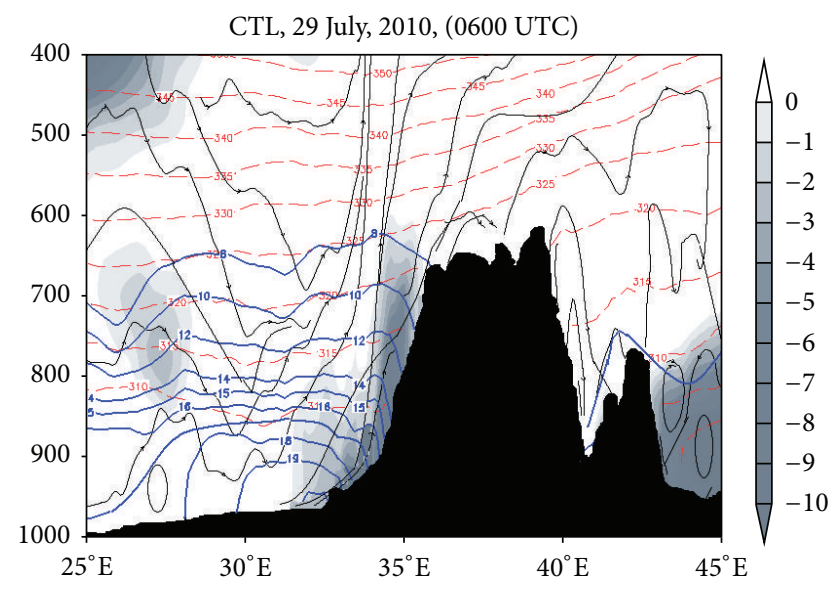

FIGURE 9: Latitude-height cross section of zonal wind (streamlines), horizontal wind (shaded), and specific humidity at 0600 UTC on $29 \mathrm{July}, 2010$, at $73^{\circ} \mathrm{E}$. Moisture flow indicated by blue lines is transported from the Arabian Sea to the north mountainous part of Pakistan (Islamabad is at $73^{\circ} \mathrm{E}$ and $33.7^{\circ} \mathrm{N}$ ).

strong eddy advection producing the heavy rainfall in both regions as in Figure 12(e). In LOW case, the EKE have higher frequency in the foothills of the Himalaya along the eastern borders of Pakistan, but it is completely absent over the Hindukush region (Figure 13(b)). Hence, it is confirmed that reduction in topography suppresses the vertical convection and decreases the resultant rainfall. In HkPZ precipitation rather disappeared after reducing the topography by half.

To examine the thermal effect of topography on the rainfall, the response of anomalies of the surface heat fluxes has been analyzed for CTL and LOW cases as in Figures 12(c) and $12(\mathrm{~d})$. Latent heat is released when water vapor changes its phase resulting in increasing the atmospheric instability. It enhances the convection and intensifies the storm. Latent heat flux in CTL case is considerably higher than LOW case in both regions and is consistent with the rainfall distribution as in Figures 12(e) and 12(f). The huge convection has been observed over HkPZ and HmPZ in the CTL case, where release of latent heat flux enhanced the intrinsic instability resulting in increased rainfall. However, it is missing in the LOW case over HkPZ.

The latent heat and sensible heat energy in the atmosphere drive the movement of the air parcels, which create wind and vertical motions. Figure 12(d) illustrates the significant increase in sensible heat flux in the Hindukush region, when the topography is reduced by $50 \%$. The sensible heat indicates the stable environment and is related to the increase in temperature in an area, mainly coming from the sunlight or by air itself. The increase in sensible heat in LOW case coincides with the respective case over the Hindukush region as indicated in Figure 12(f).

Lower values of OLR in the CTL case indicate the deep convection in both $\mathrm{HmPZ}$ and $\mathrm{HkPZ}$ regions. The anomaly of OLR in Figure 13(a) indicates that it has larger values in LOW case indicating the cloud free region having high ground surface temperature. Figure 13(b) presents the anomaly of the low clouds that is also coherent with the earlier findings. Figure 13(c) shows the moisture is converging along both the regions at $850 \mathrm{hPa}$, yielding a heavy stratiform precipitation over vast area in the CTL case, whereas the circulation over the central Punjab becomes weak in LOW case and moisture is being transported towards west over the Afghanistan Plateau.

\section{Conclusions and Discussions}

The rain across the big mountain range lying on the path way of winds and weather system like monsoon is one of the confident expectations in the atmospheric sciences. 


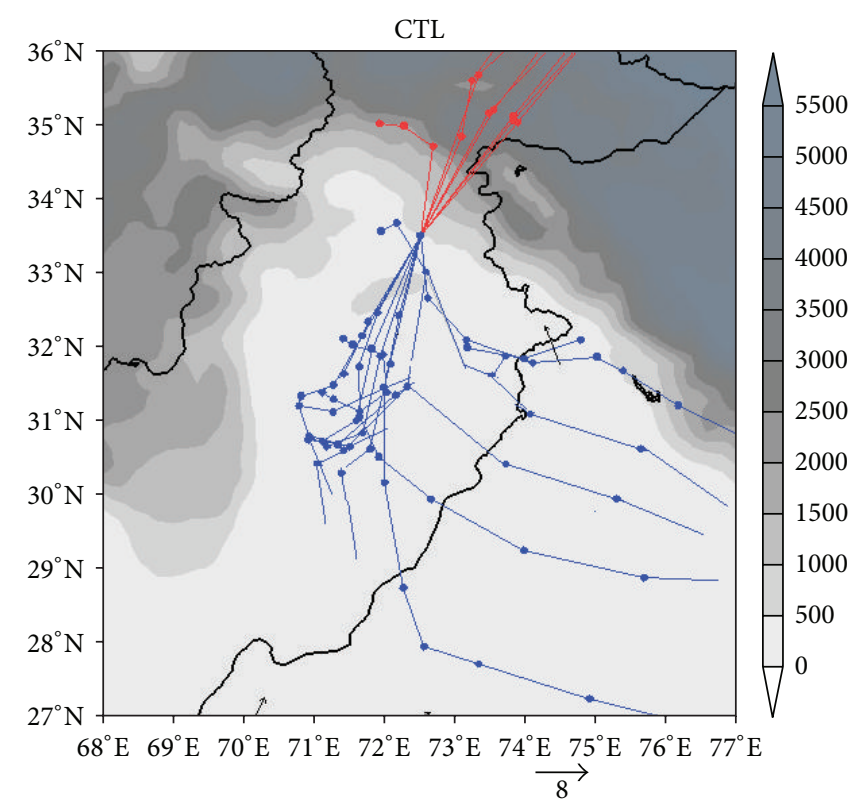

(a)

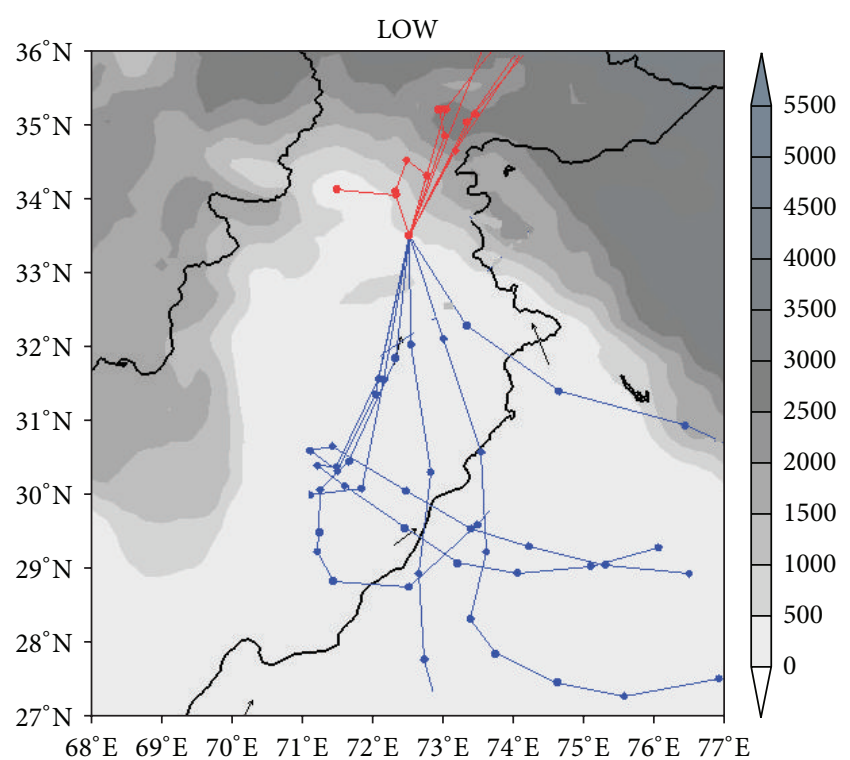

(b)

FIGURE 10: Trajectories showing path of air parcels transported from the BoB/Arabian Sea, passing through a point south of the HmPZ in the control case (CTL) (a) and lower topography case (LOW) (b). The shaded contours are terrain heights.

Precipitation maximizes over the windward slopes of the large mountain ranges; however, its amplitude, spatial distribution, and relationship with orography are much more complex questions. The air motion in mountains is strongly modified by terrain, and different sectors of storms are decipherable by changes in the vertical profile of water contents and precipitation processes. This study is focused on exploring the relative impact of orography and thermodynamics on heavy precipitation event in north Pakistan. The July 2010 heavy precipitation event over north Pakistan was selected and its synoptic situation is analyzed. A deep trough at $300 \mathrm{hPa}$ divided the normal high into Eurasia and Chinese parts. The split high developed imposingly and shifted $10^{\circ}$ eastward of its climatological position. It was exceptionally warm by up to $8^{\circ} \mathrm{C}$, centered over China. The Russian high acted as blocking pattern. The trough created hook-like shape in the north of Pakistan at lower level, bringing cold and drier air to this region. Before the occurrence of this event, Tibetan High was strong enough and its center oscillated between $30^{\circ} \mathrm{N}$ and $40^{\circ} \mathrm{N}$. The seasonal low over Baluchistan shifted southward and changes its orientation, bringing warm moisture flow from the Arabian Sea to this region. The seasonal low over India shifted northward and pressure gradient is created along Himalayan foothills resulting into enhanced moisture flux from BoB into north Pakistan. The mesoscale convection in the high mountainous region was enhanced by the upslope flow. The dry and cold sinking air from the north sets a platform for rising of warm and moist air from $\mathrm{BoB}$ and the Arabian Sea over the mountainous region, creating favorable situation for growth of heavy precipitation system in northern Pakistan. ITCZ responds linearly to the heating of Tibetan High over the Himalayan region, by an abrupt northward shifting causing monsoonal cloud burst over north Pakistan.

To further investigate the topographic impact on this heavy rainfall event, WRF model coupled with Morrison double moment scheme was used, with three nested domains of $27 \mathrm{~km}, 9 \mathrm{~km}$, and $3 \mathrm{~km}$ resolution, respectively. Two sensitivity tests with full topography (CTL) and reduced topography by $50 \%$ (LOW) were carried out for the period of 27-30 July. The CTL run was in best match with the reanalysis data output. The presence of tall and wider mountain range in north Pakistan gives birth to more robust microphysical growth processes at lower levels on windward side and precipitation is usually experienced on lower slopes of the terrain. Two distinct precipitation features were identified over Hindukush and Himalaya. The wind convergence zones also followed the precipitation features. Trajectory analysis also indicated that blockage of sub- $500 \mathrm{hPa}$ flow in CTL case over Himalayan mountains led to formation of easterly barrier jet on its southward side. It results in moisture transport to the upper atmosphere and large scale convection. Intense convection over upslope occurred when moist circulation intersected a steep mountain range rising above the LCL. During the change of phase, the release of latent heat further deepens the convection. Consequently, Hindukush and Himalaya regions got intensified rainfall between $32^{\circ} \mathrm{N}$ and $35^{\circ} \mathrm{N}$ in the CTL simulation. However, in LOW case, the precipitation zone over Hindukush region disappeared. It may be explained by the anomalous divergence exhibited at the lower level resulting in suppressed convection. The EKE analysis indicates that the higher the mountain, the greater the frequency of the mesoscale disturbances. In LOW case, EKE is absent over Hindukush, which results in diminishing 
Vorticity, CAPE, and moisture flux, 28 July (1200 UTC) CTL

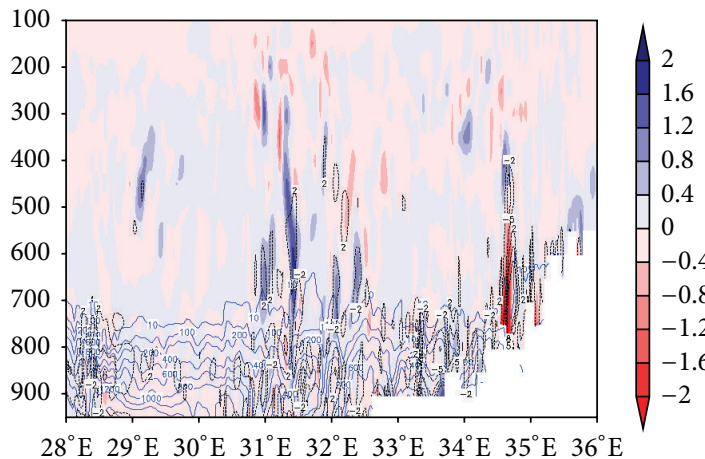

(a)

Vorticity, CAPE, and moisture flux, 28 July (1800 UTC) CTL

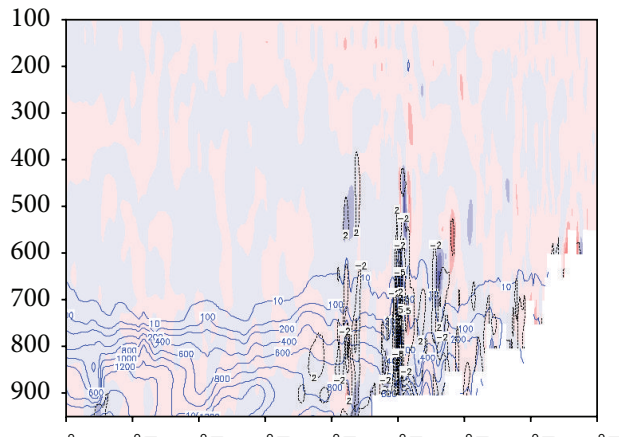

$28^{\circ} \mathrm{E} 29^{\circ} \mathrm{E} 30^{\circ} \mathrm{E} 31^{\circ} \mathrm{E} 32^{\circ} \mathrm{E} 33^{\circ} \mathrm{E} 34^{\circ} \mathrm{E} 35^{\circ} \mathrm{E} 36^{\circ} \mathrm{E}$

(b)

Vorticity, CAPE, and moisture flux, 29 July (0000 UTC) CTL

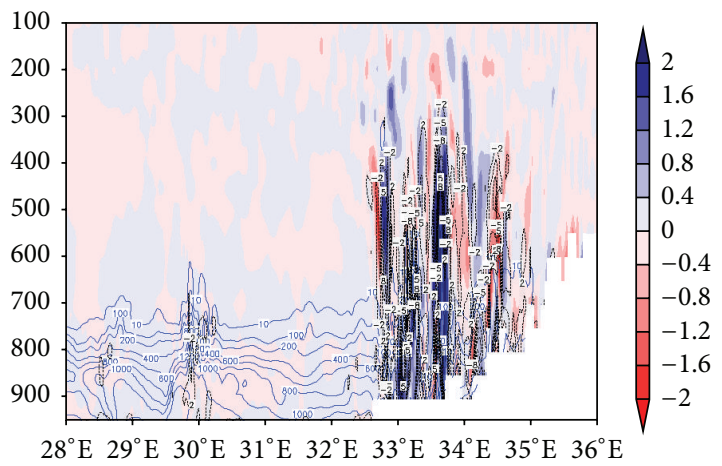

(c)

Vorticity, CAPE, and moisture flux, 29 July (0600 UTC) CTL

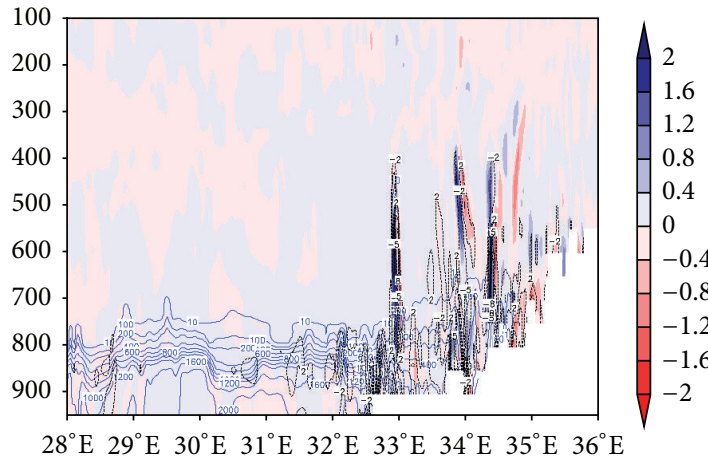

(d)
Vorticity, CAPE, and moisture flux, 28 July (1200 UTC) LOW

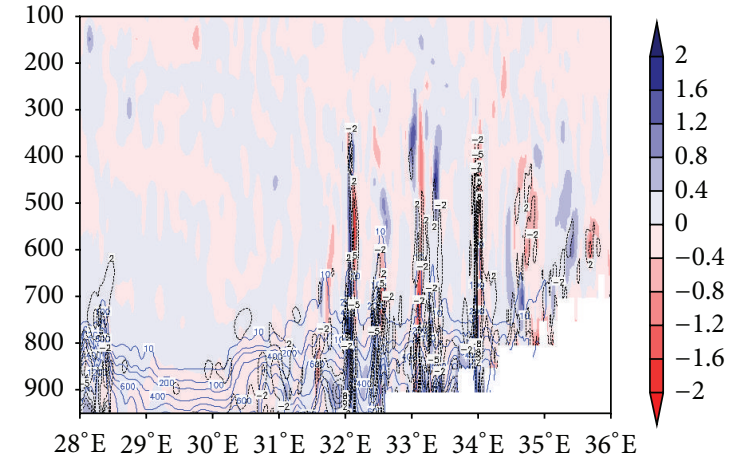

(e)

Vorticity, CAPE, and moisture flux, 28 July (1800 UTC) LOW

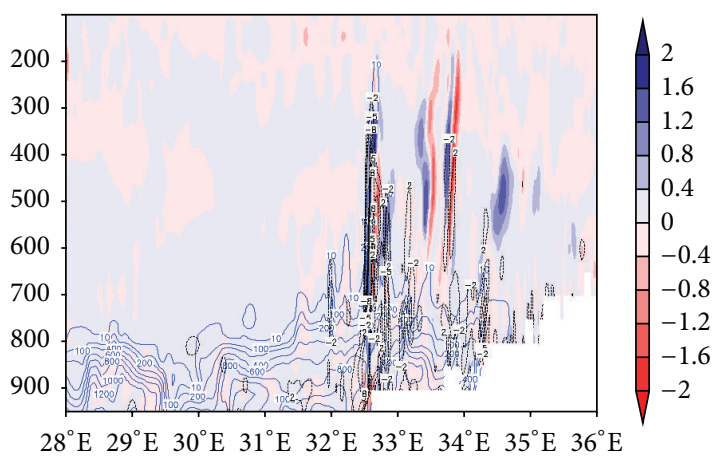

(f)

Vorticity, CAPE, and moisture flux, 29 July (0000 UTC) LOW

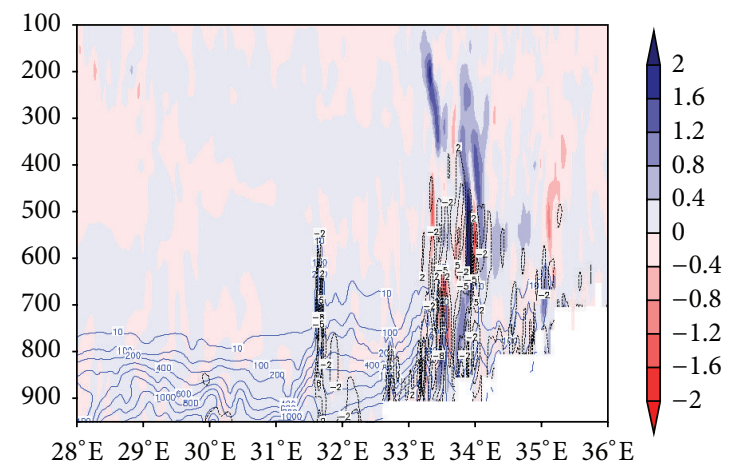

(g)

Vorticity, CAPE, and moisture flux, 29 July (0600 UTC) LOW

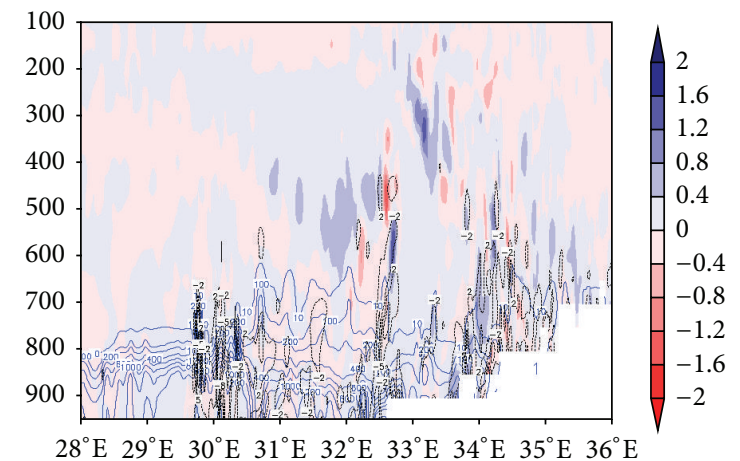

(h)

FIGURE 11: Time evolution of longitude height cross section of vorticity (colored), convective available potential energy (CAPE) (blue lines) moisture flux (black lines) for (a) CTL case ((a)-(d)) left pane and (b) LOW case ((e)-(h)) right pane at $73^{\circ} \mathrm{E}$. 
EKE, CTL

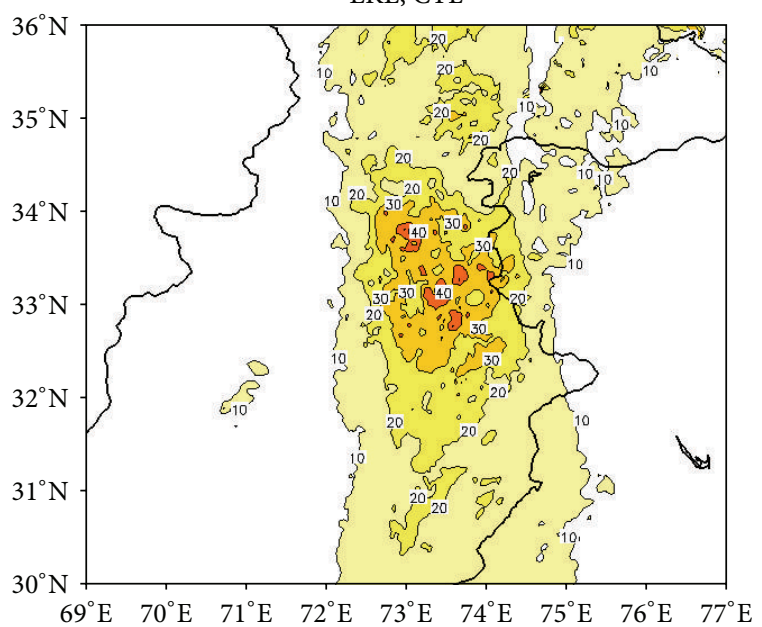

(a)

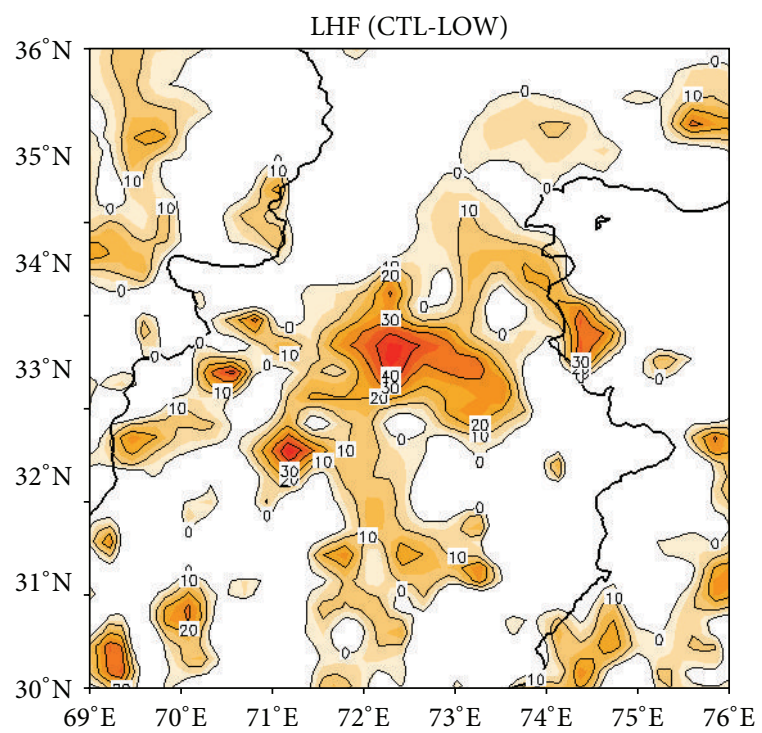

(c)

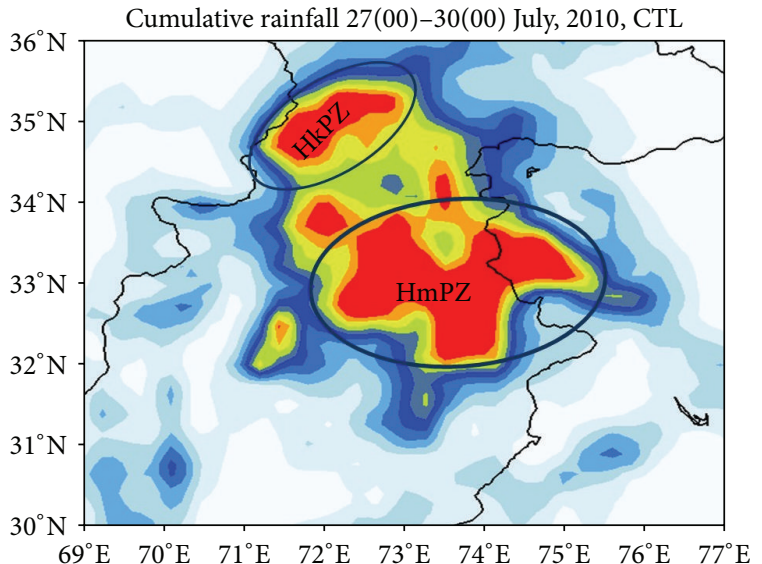

(e)

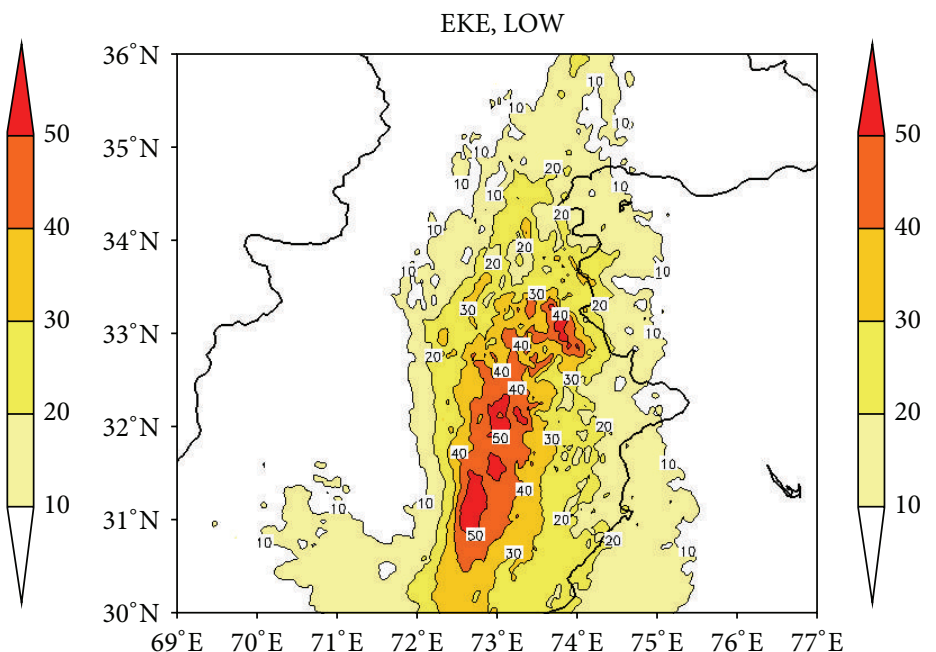

(b)

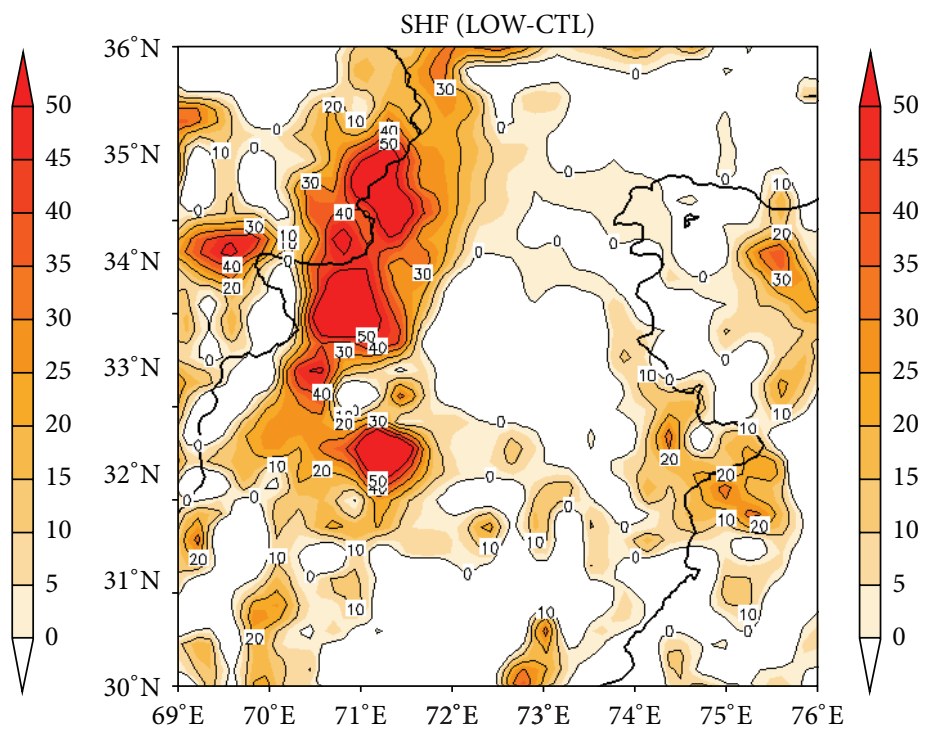

(d)

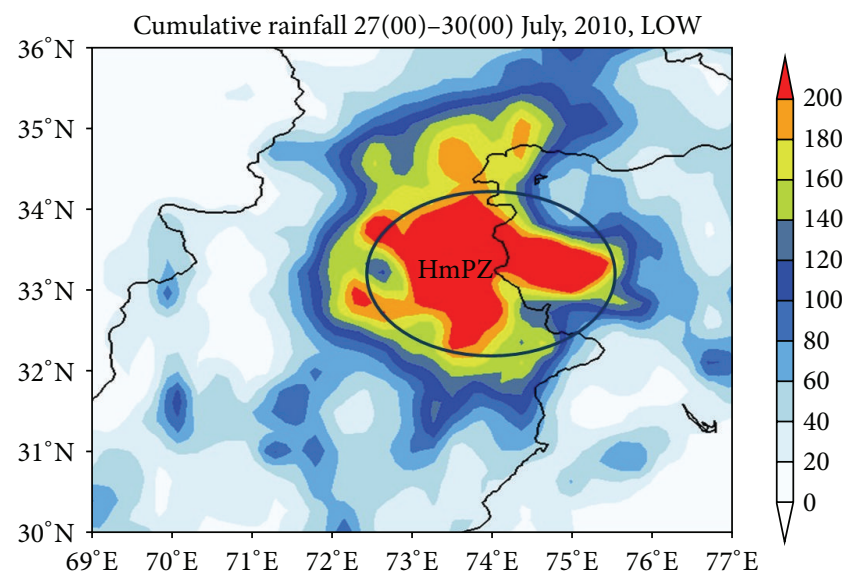

(f)

FIGURE 12: (a) Eddy kinetic energy for CTL case, (b) eddy kinetic energy for LOW case, (c) difference of latent heat flux of CTL case to the LOW case, (d) difference of sensible heat flux of CTL case to the LOW case, (e) cumulative rainfall for CTL case, and (f) cumulative rainfall for LOW case. 


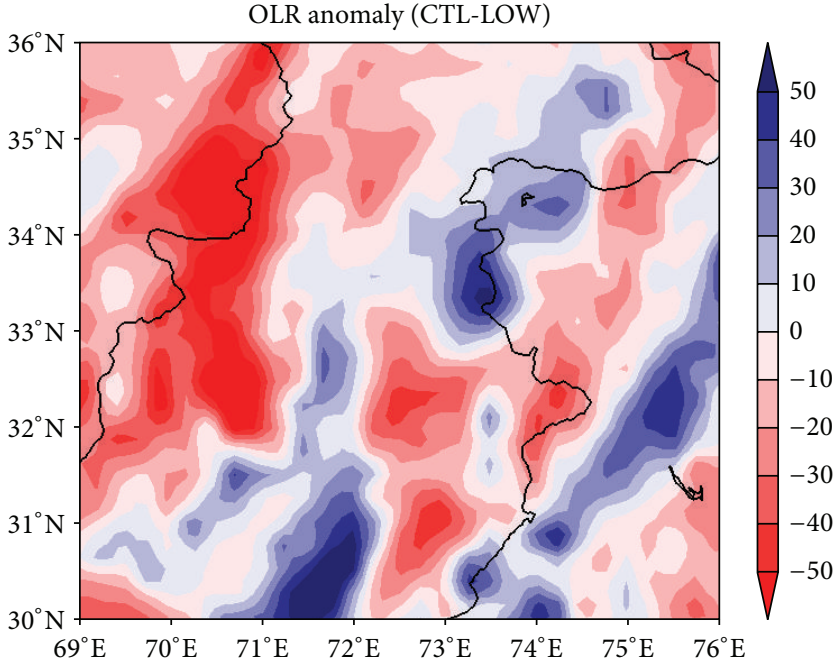

(a)

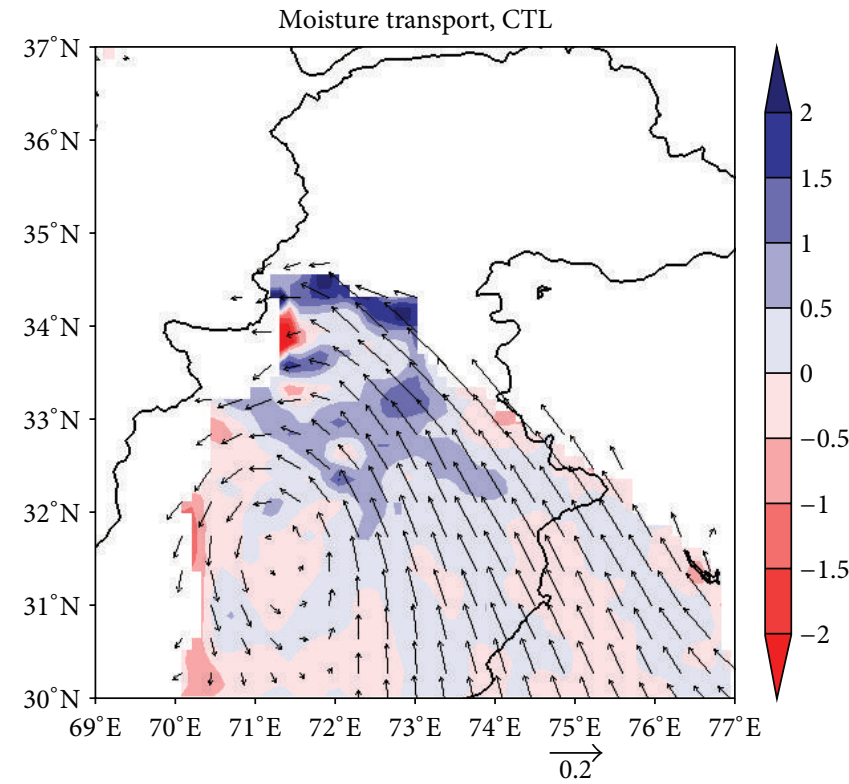

(c)

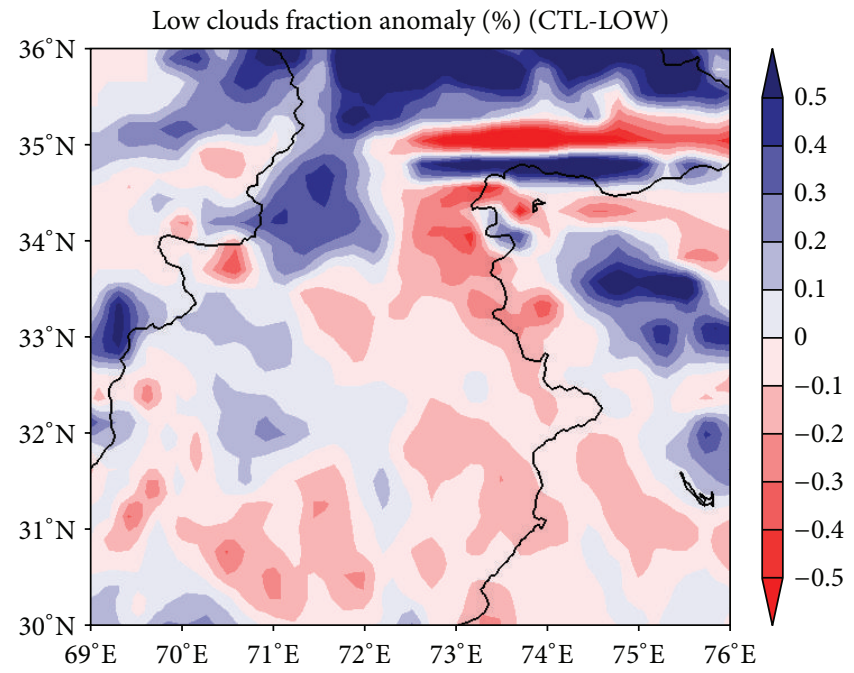

(b)

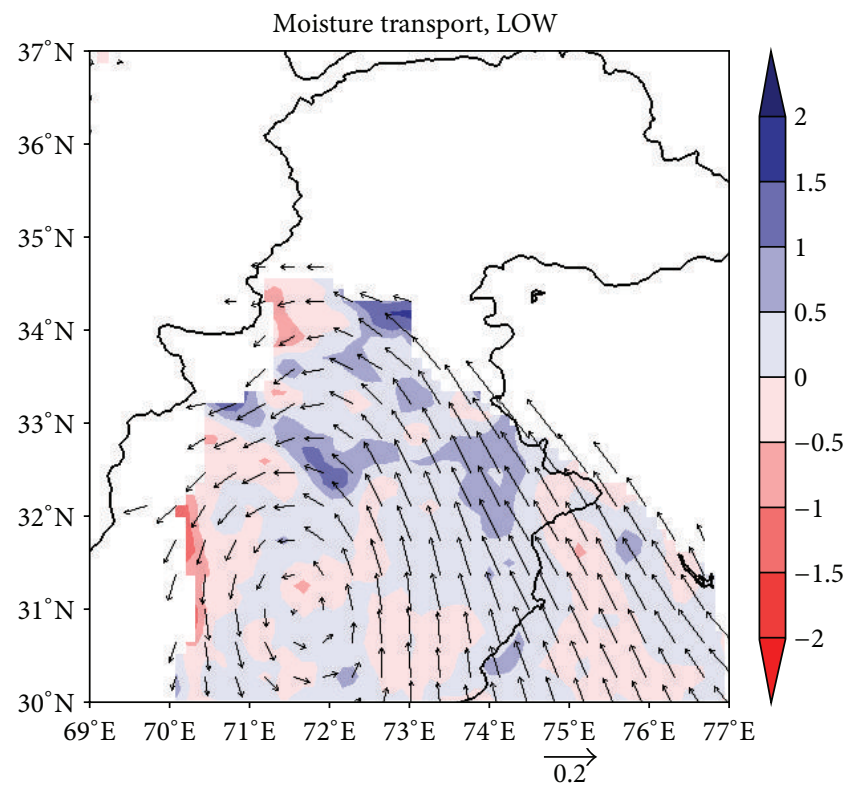

(d)

FIGURE 13: (a) Outgoing long wave radiation (OLR) anomaly $\left(\mathrm{W} \mathrm{m}^{-2}\right)$, (b) low cloud fraction anomaly, (c) moisture convergence colored and moisture transport of CTL case, and (d) moisture convergence colored and moisture transport of LOW case, for the period 1200 UTC of 28 July to 0600 UTC of 29 July, 2010.

the precipitation zone in this region. OLR anomaly and low cloud fraction also supported the findings. Land sea temperature distribution, regional circulations, and orography in this particular region laid down the perfect conditions favorable for the occurrence of this extreme event. The spatial distribution of the CAPE and moisture flux indicates the enhanced instability in the CTL case as compared to the LOW case. It results in deep mesoscale convective cores and precipitation in the region. It helps in the release of latent heat energy due to the phase change. Energy, released, warms the atmosphere and causes further enhancing of convection and intensifying of the storms. The reduction in topography results in decreased convective instability in the atmosphere.
It has been concluded that topography plays a key role in the occurrence of the extreme event of July 2010 and is supported by the relevant heat fluxes and regional circulations. It turned into deep convective storm and produced heavy rainfall.

\section{Disclosure}

Khan Muhammad Tahir is the first author.

\section{Conflict of Interests}

The authors declare that there is no conflict of interests regarding the publication of this paper. 


\section{Acknowledgments}

This study was jointly sponsored by the China Meteorological Administration, Pakistan Meteorological Department, National Science Foundation of China (Grant no. 91337101), the special fund for doctorate programs in Chinese Universities (20113228110002), and the Priority Academic Program of the Development of Jiangsu Higher Education Institutions (PAPD). The authors are also thankful to the CIE, Nanjing University of Science and Technology, for providing the requisite lab facilities and all other forms of support.

\section{References}

[1] D. Mooley and J. Shukla, "Variability and forecasting of the summer monsoon rainfall over India," in Monsoon Meteorology, C. P. Chang and T. N. Krishnamurti, Eds., pp. 26-59, Oxford University Press, 1987.

[2] K. L. Rasmussen and R. A. Houze Jr., "A flash-flooding storm at the steep edge of high terrain: disaster in the Himalayas," Bulletin of the American Meteorological Society, vol. 93, no. 11, pp. 1713-1724, 2012.

[3] P. J. Webster, "The elementary monsoon," in Monsoons, J. S. Fein and P. L. Stephens, Eds., pp. 3-32, John Wiley and Sons, 1987.

[4] C. Ramage, Monsoon Meteorology, vol. 15 of International Geophysics Series, Academic Press, New York, NY, USA, 1971.

[5] H. L. Kuo and Y.-F. Qian, "Numerical simulation of the development of mean monsoon circulation in July," Monthly Weather Review, vol. 110, no. 12, pp. 1879-1897, 1982.

[6] C. Chou, "Land-sea heating contrast in an idealized Asian summer monsoon," Climate Dynamics, vol. 21, no. 1, pp. 11-25, 2003.

[7] X. Liang, Y. Liu, and G. Wu, "The role of land-sea distribution in the formation of the Asian summer monsoon," Geophysical Research Letters, vol. 32, no. 3, 2005.

[8] Q. H. Jin, J. H. He, and L. X. Chen, "Impact of ocean-continent distribution over southern Asia on the formation of summer monsoon," Acta Meteorologica Sinica, vol. 1, article 009, 2006.

[9] A. P. Barros, S. Chiao, T. J. Lang, D. Burbank, and J. Putkonen, "From weather to climate-seasonal and interannual variability of storms and implications for erosion processes in the Himalaya," Special Paper of the Geological Society of America, vol. 398, pp. 17-38, 2006.

[10] C. Li and M. Yanai, "The onset and interannual variability of the asian summer monsoon in relation to land-sea thermal contrast," Journal of Climate, vol. 9, no. 2, pp. 358-375, 1996.

[11] Y. F. Qian, Y. Q. Zheng, Y. Zhang, and M. Q. Miao, "Responses of China's summer monsoon climate to snow anomaly over the Tibetan Plateau," International Journal of Climatology, vol. 23, no. 6, pp. 593-613, 2003.

[12] U. Romatschke and R. A. Houze Jr., "Extreme summer convection in South America," Journal of Climate, vol. 23, no. 14, pp. 3761-3791, 2010.

[13] Y. Liu, B. J. Hoskins, and M. Blackburn, "Impact of Tibetan orography and heating on the summer flow over Asia," Journal of the Meteorological Society of Japan, vol. 85, pp. 1-19, 2007.

[14] G. Wu, Y. Liu, T. Wang et al., "The influence of mechanical and thermal forcing by the Tibetan Plateau on Asian climate," Journal of Hydrometeorology, vol. 8, no. 4, pp. 770-789, 2007.

[15] G. H. Roe, "Orographic precipitation," Annual Review of Earth and Planetary Sciences, vol. 33, pp. 645-671, 2005.
[16] A. P. Barros, G. Kim, E. Williams, and S. W. Nesbitt, "Probing orographic controls in the Himalayas during the monsoon using satellite imagery," Natural Hazards and Earth System Science, vol. 4, no. 1, pp. 29-51, 2004.

[17] E. J. Zipser, D. J. Cecil, C. Liu, S. W. Nesbitt, and D. P. Yorty, "Where are the most intense thunderstorms on Earth?" Bulletin of the American Meteorological Society, vol. 87, no. 8, pp. 10571071, 2006.

[18] R. A. Houze, D. C. Wilton, and B. F. Smull, "Monsoon convection in the Himalayan region as seen by the TRMM precipitation radar," Quarterly Journal of the Royal Meteorological Society, vol. 133, no. 627, pp. 1389-1411, 2007.

[19] F. Caracena, R. A. Maddox, L. R. Hoxiy, and C. F. Chappell, "Mesoanalysis of the Big Thompson storm," Monthly Weather Review, vol. 107, no. 1, pp. 1-17, 1979.

[20] P. Berg, J. O. Haerter, P. Thejll, C. Piani, S. Hagemann, and J. H. Christensen, "Seasonal characteristics of the relationship between daily precipitation intensity and surface temperature," Journal of Geophysical Research D: Atmospheres, vol. 114, no. 18, Article ID D18102, 2009.

[21] C.-K. Yu and B. F. Smull, "Airborne doppler observations of a landfalling cold front upstream of steep coastal orography," Monthly Weather Review, vol. 128, no. 6, pp. 1577-1603, 2000.

[22] T. R. Parish, "Barrier winds along the Sierra Nevada Mountains.", Journal of Applied Meteorology, vol. 21, no. 7, pp. 925-930, 1982.

[23] J. E. Overland, "Scale analysis of marine winds in straits and along mountainous coasts.", Monthly Weather Review, vol. 112, no. 12, pp. 2530-2534, 1984.

[24] G. M. Lackmann and J. E. Overland, "Atmospheric structure and momentum balance during a gap-wind event in Shelikof Strait, Alaska," Monthly Weather Review, vol. 117, no. 8, pp. 1817$1833,1989$.

[25] J. E. Overland and N. A. Bond, "Observations and scale analysis of coastal wind jets," Monthly Weather Review, vol. 123, no. 10, pp. 2934-2941, 1995.

[26] J. D. Doyle, “The influence of mesoscale orography on a coastal jet and rainband," Monthly Weather Review, vol. 125, no. 7, pp. 1465-1488, 1997.

[27] "Meteorological conditions for the formation of rain. By J. Bjerknes and H. Solberg. Kristiania, Geofyaiske Publikationer, 2, No. 3, 1921. 4॰. Pp. 60, map," Quarterly Journal of the Royal Meteorological Society, vol. 48, no. 204, pp. 374-375, 1922.

[28] Y.-L. Lin, S. Chiao, T.-A. Wang, M. L. Kaplan, and R. P. Weglarz, "Some common ingredients for heavy orographic rainfall," Weather Forecasting, vol. 16, pp. 633-660, 2001.

[29] N. C. Witcraft, Y.-L. Lin, and Y.-H. Kuo, "Dynamics of orographic rain associated with the passage of a tropical cyclone over a mesoscale mountain," Terrestrial, Atmospheric and Oceanic Sciences, vol. 16, no. 5, pp. 1133-1161, 2005.

[30] C.-S. Chen, Y.-L. Lin, W.-C. Peng, and C.-L. Liu, "Investigation of a heavy rainfall event over southwestern Taiwan associated with a subsynoptic cyclone during the 2003 Mei-Yu season," Atmospheric Research, vol. 95, no. 2-3, pp. 235-254, 2010.

[31] S. Medina and R. A. Houze Jr., "Air motions and precipitation growth in Alpine storms," Quarterly Journal of the Royal Meteorological Society, vol. 129, pp. 345-371, 2003.

[32] O. Bousquet and B. F. Smull, "Observed mass transports accompanying upstream orographic blocking during MAP IOP8," Quarterly Journal of the Royal Meteorological Society, vol. 132, no. 620, pp. 2393-2413, 2006. 
[33] R. A. Houze Jr., "Mesoscale convective systems," Reviews of Geophysics, vol. 42, no. 4, 2004.

[34] R. A. Houze Jr., K. L. Rasmussen, S. Medina, S. R. Brodzik, and U. Romatschke, "Anomalous atmospheric events leading to the summer 2010 floods in Pakistan," Bulletin of the American Meteorological Society, vol. 92, no. 3, pp. 291-298, 2011.

[35] R. A. Houze Jr., "Orographic effects on precipitating clouds," Reviews of Geophysics, vol. 50, no. 1, 2012.

[36] W. K. M. Lau and K.-M. Kim, "The 2010 Pakistan flood and Russian heat wave: teleconnection of hydrometeorological extremes," Journal of Hydrometeorology, vol. 13, no. 1, pp. 392403, 2012.

[37] T. J. Galarneau Jr., T. M. Hamill, R. M. Dole, and J. Perlwitz, "A multiscale analysis of the extreme weather events over Western Russia and Northern Pakistan during July 2010," Monthly Weather Review, vol. 140, no. 5, pp. 1639-1664, 2012.

[38] K.-M. Xu and K. A. Emanuel, "Is the tropical atmosphere conditionally unstable?" Monthly Weather Review, vol. 117, no. 7, pp. 1471-1479, 1989.

[39] Y. Liu, G. Wu, J. Hong et al., "Revisiting Asian monsoon formation and change associated with Tibetan Plateau forcing: II. Change," Climate Dynamics, vol. 39, no. 5, pp. 1183-1195, 2012.

[40] B. Hoskins and P. Berrisford, "A potential vorticity perspective of the storm of 15-16 October 1987," Weather, vol. 43, no. 3, pp. 122-129, 1988.

[41] R. W. Moore, M. T. Montgomery, and H. C. Davies, "The integral role of a diabetic rossby vortex in a heavy snowfall event," Monthly Weather Review, vol. 136, no. 6, pp. 1878-1897, 2008.

[42] D.-L. Zhang, Y. Liu, and M. K. Yau, "A multiscale numerical study of hurricane Andrew (1992). Part V: inner-core thermodynamics," Monthly Weather Review, vol. 130, no. 11, pp. 27452763, 2002.

[43] J. S. Fein and J. P. Kuettner, "Report on the summer MONEX field phase," Bulletin of the American Meteorological Society, vol. 61, pp. 461-474, 1980.

[44] H. Morrison, J. A. Curry, and V. I. Khvorostyanov, "A new double-moment microphysics parameterization for application in cloud and climate models. Part I: description," Journal of the Atmospheric Sciences, vol. 62, no. 6, pp. 1665-1677, 2005.

[45] B. Baker, C. Schmitt, P. Lawson, and D. Mitchell, "Further analysis and improvements of ice crystal mass-size relationships," in Proceedings of the 11th Conference on Cloud Physics, P2.15, American Meteorological Society, Ogden, Utah, USA, June 2002.

[46] M. J. Iacono, E. J. Mlawer, S. A. Clough, and J.-J. Morcrette, "Impact of an improved longwave radiation model, RRTM, on the energy budget and thermodynamic properties of the NCAR community climate model, CCM3," Journal of Geophysical Research D: Atmospheres, vol. 105, no. 11, pp. 14873-14890, 2000.

[47] J. S. Kain and J. M. Fritsch, "Convective parameterization for mesoscale models: the Kain-Fritsch scheme'. The representation of cumulus convection in numerical models," Meteorological Monographs, vol. 46, pp. 165-170, 1993, Fei Chen and Dudhia, 2001.

[48] F. Chen and J. Dudhia, "Coupling and advanced land surfacehydrology model with the Penn State-NCAR MM5 modeling system. Part I: model implementation and sensitivity," Monthly Weather Review, vol. 129, no. 4, pp. 569-585, 2001.

[49] S.-Y. Hong, Y. Noh, and J. Dudhia, "A new vertical diffusion package with an explicit treatment of entrainment processes," Monthly Weather Review, vol. 134, no. 9, pp. 2318-2341, 2006.
[50] B. E. Mapes, T. T. Warner, and M. Xu, "Diurnal patterns of rainfall in northwestern South America. Part III: diurnal gravity waves and nocturnal convection offshore," Monthly Weather Review, vol. 131, no. 5, pp. 830-844, 2003.

[51] H. Flohn, 'Large-scale aspects of the 'summer monsoon' in south and east Asia," Journal of the Meteorological Society of Japan, vol. 75, pp. 180-186, 1957.

[52] H. Luo and M. Yanai, "The large-scale circulation and heat sources over the Tibetan Plateau and surrounding areas during the early summer of 1979. Part II: heat and moisture budgets," Monthly Weather Review, vol. 112, no. 5, pp. 966-989, 1984.

[53] M. Yanai and C. Li, "Mechanism of heating and the boundary layer over the Tibetan Plateau," Monthly Weather Review, vol. 122, no. 2, pp. 305-323, 1994.

[54] S. Solomon, Climate Change 2007-The Physical Science Basis: Working Group I Contribution to the Fourth Assessment Report of the Ipcc, vol. 4, Cambridge University Press, Cambridge, UK, 2007.

[55] E. Kalnay, M. Kanamitsu, R. Kistler et al., "The NCEP/NCAR 40-year reanalysis project," Bulletin of the American Meteorological Society, vol. 77, no. 3, pp. 437-471, 1996.

[56] T. Krishnamurti and R. Hawkins, "Mid-tropospheric cyclones of the southwest monsoon," Journal of Applied Meteorology, vol. 9, no. 3, pp. 442-458, 1970.

[57] C. F. Chappell, "Quasi-stationary convective events," in Mesoscale Meteorology and Forecasting, pp. 289-310, American Meteorological Society, 1986.

[58] S. Bhushan and A. P. Barros, "A numerical study to investigate the relationship between moisture convergence patterns and orography in Central Mexico," Journal of Hydrometeorology, vol. 8, no. 6, pp. 1264-1284, 2007.

[59] G. J. Tripoli and W. R. Cotton, "Numerical study of an observed organic mesoscale convective system. Part 1: simulated genesis and comparison with observations," Monthly Weather Review, vol. 117, no. 2, pp. 273-304, 1989.

[60] J. D. Marwitz, "Deep orographic storms over the Sierra Nevada. Part I: thermodynamic and kinematic structure," Journal of the Atmospheric Sciences, vol. 44, no. 1, pp. 159-173, 1987.

[61] O. Bousquet and B. F. Smull, "Airflow and precipitation fields within deep alpine valleys observed by airborne Doppler radar," Journal of Applied Meteorology, vol. 42, no. 10, pp. 1497-1513, 2003.

[62] O. Bousquet and B. F. Smull, "Airflow and precipitation fields within deep Alpine valleys observed by airborne Doppler radar," Journal of Applied Meteorology, vol. 42, no. 10, pp. 1497-1513, 2003.

[63] M. F. Garvert, B. Smull, and C. Mass, "Multiscale mountain waves influencing a major orographic precipitation event," Journal of the Atmospheric Sciences, vol. 64, no. 3, pp. 711-737, 2007.

[64] B. A. Colle, "Sensitivity of orographic precipitation to changing ambient conditions and terrain geometries: an idealized modeling perspective," Journal of the Atmospheric Sciences, vol. 61, no. 5, pp. 588-606, 2004. 

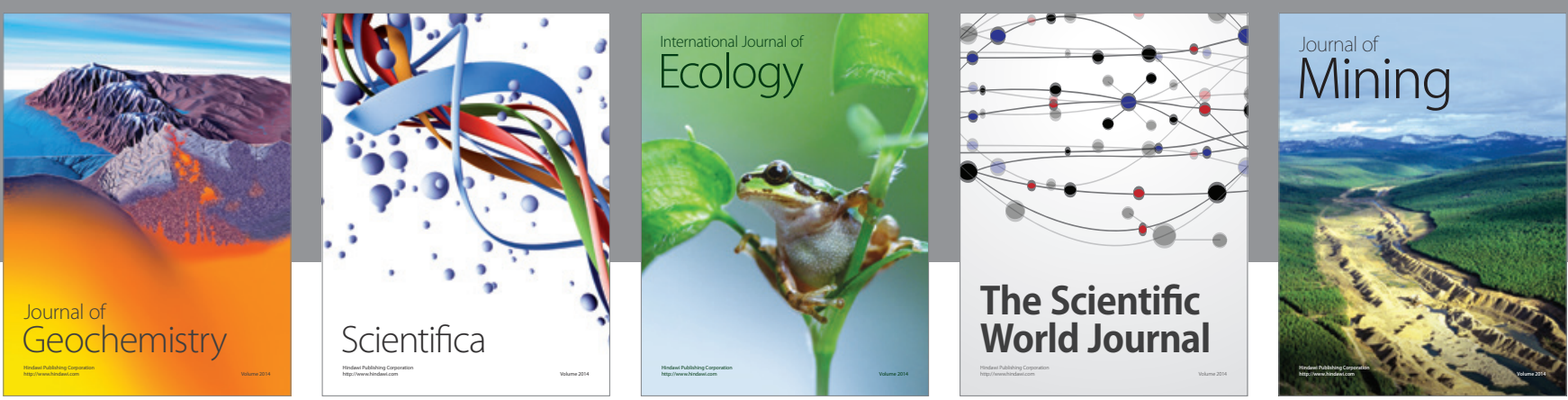

The Scientific World Journal
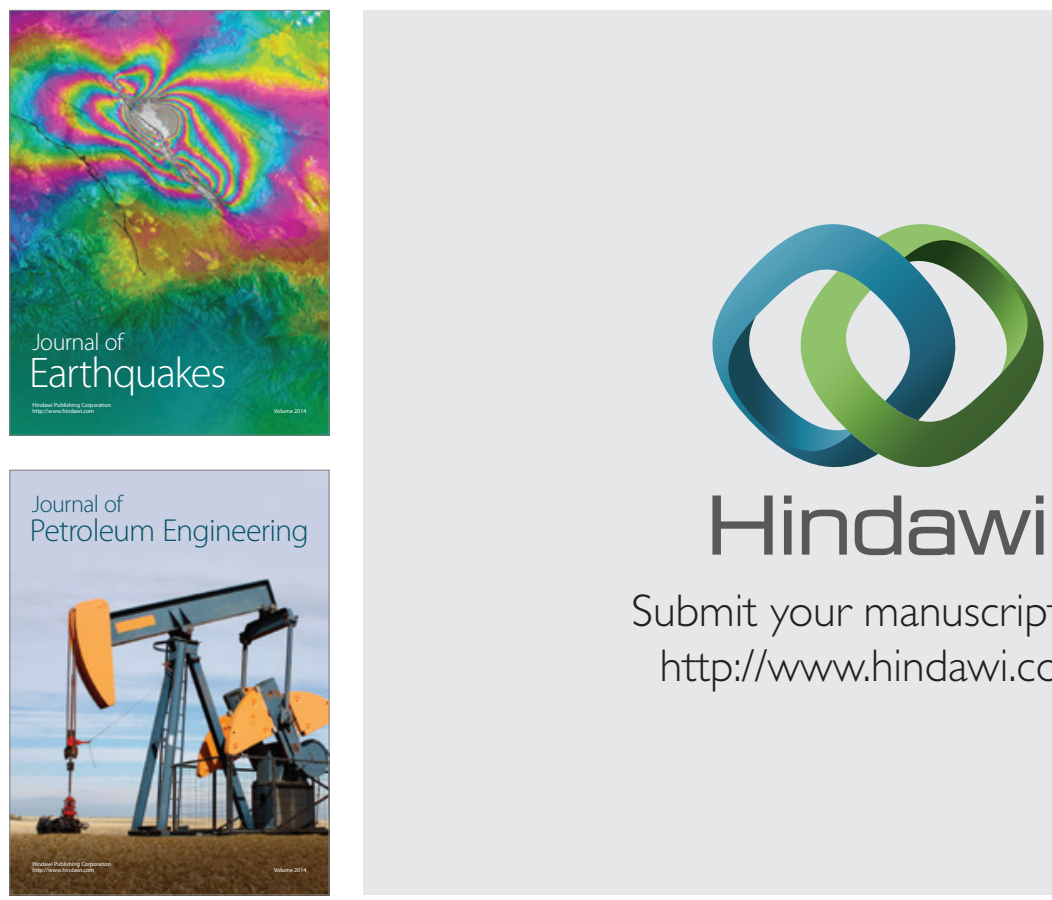

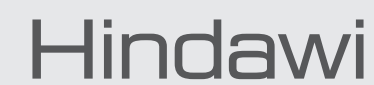

Submit your manuscripts at

http://www.hindawi.com
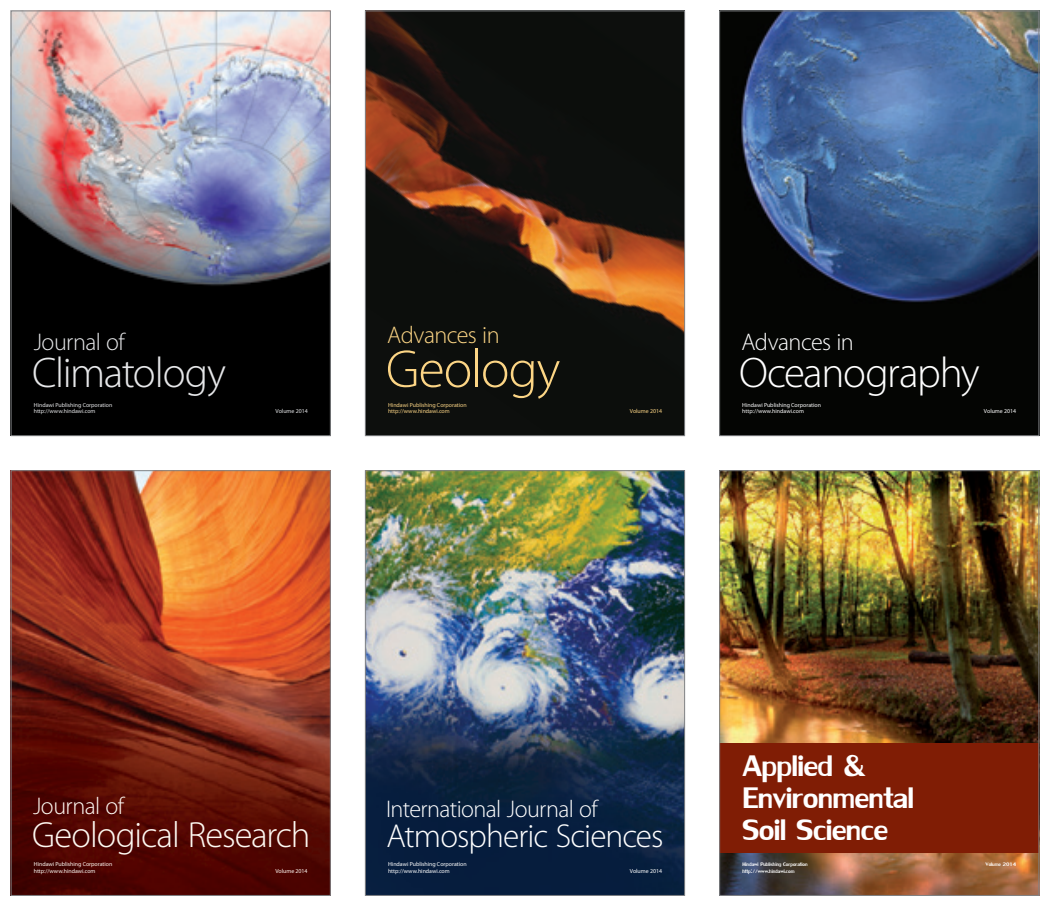
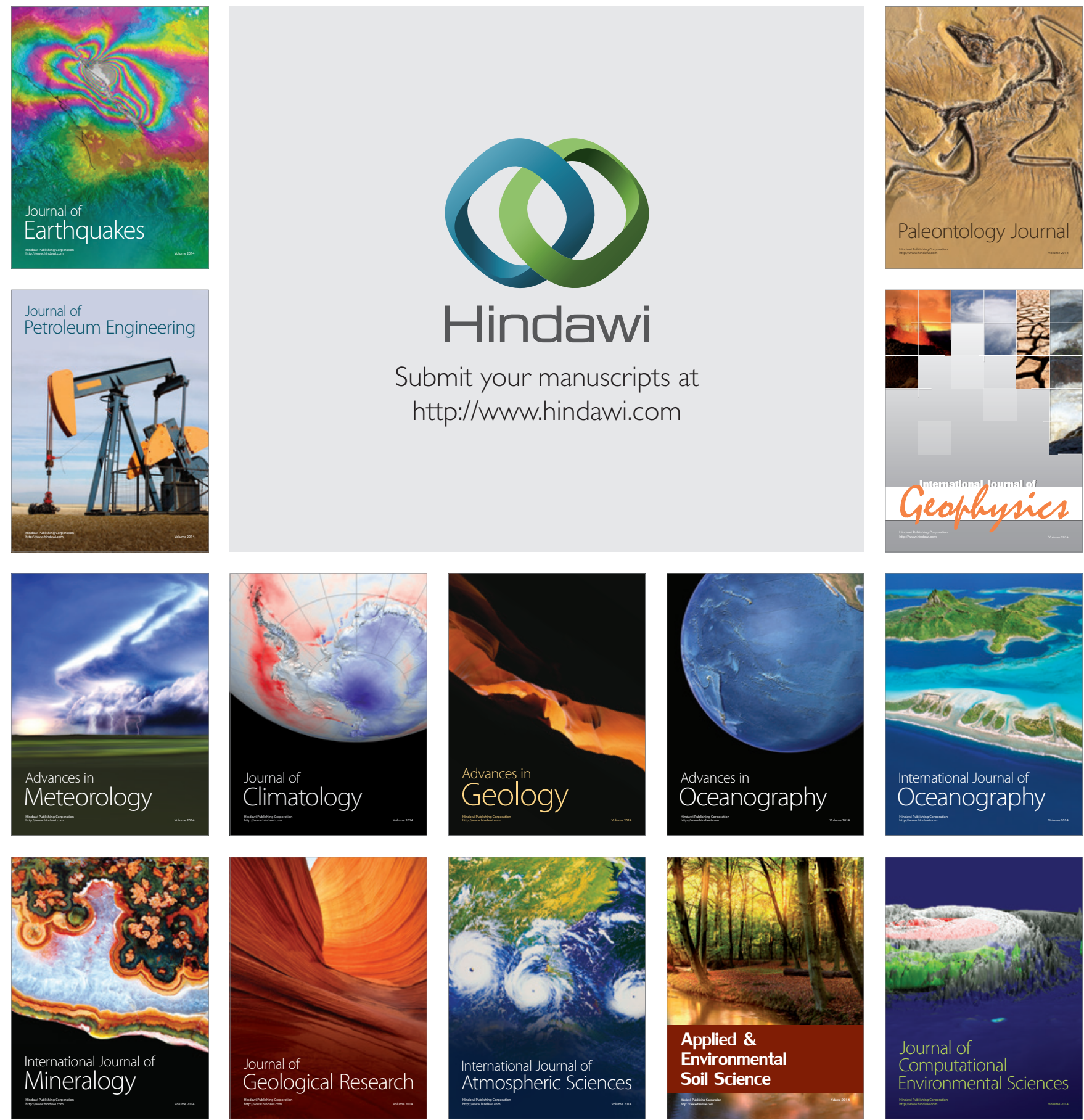